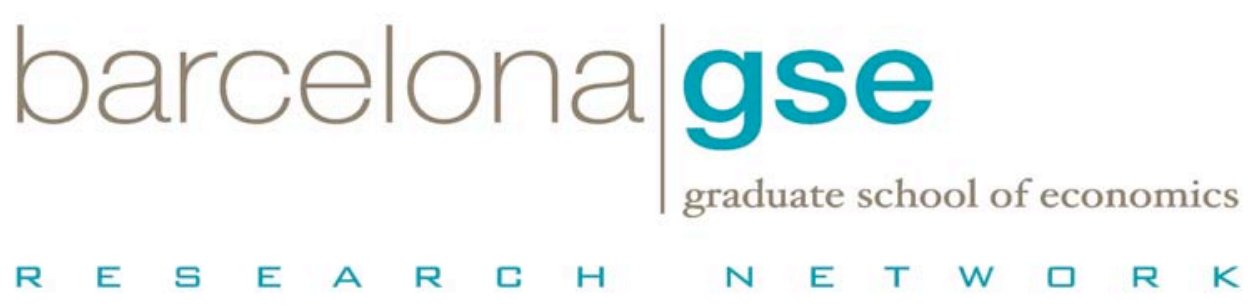

Loans, Insurance and Failures in the Credit Market for Students

Elena Del Rey and Bertrand Verheyden

August 2008

Barcelona Economics Working Paper Series

Working Paper no 359 


\title{
Loans, Insurance and Failures in the Credit Market for Students
}

\author{
Elena Del Rey*and Bertrand Verheyden ${ }^{\dagger}$
}

August 2008

\begin{abstract}
Whereas public student loans are often income contingent, private banks typically offer pure loans, or don't offer loans at all. In order to provide a rationale for these observations, we present a model with perfectly competitive banks and risk averse students who have private information on their ability to learn. We show that the combination of ex-post moral hazard and adverse selection produces credit market rationing when default penalties are low. Intermediate levels of default penalties can result in the existence of an equilibrium that pools together ability types. However, pooling contracts are not insuring at equilibrium, which implies a second type of credit market failure. Finally, if default penalties are large enough, equilibrium contracts provide less able students with insurance against the eventuality of a bad outcome, just in the income contingent loan fashion. The model is also used to explain other stylized facts, such as the positive impact of returns to education and interest rate subsidies on the development of the student loan market. Also, it explains why, unlike banks, governments offer income contingent loans.
\end{abstract}

Keywords: ex-post moral hazard, adverse selection, income contingent loans

JEL Classification: D82, I22

\footnotetext{
*Corresponding author: Universitat de Girona and FEDEA, Spain. Email: elena.delrey@udg.edu

${ }^{\dagger}$ FNRS research fellow at University of Namur, Belgium

Bertrand Verheyden gratefully acknowledges support from the Belgian National Fund for Scientific Research and University of Namur. Elena Del Rey acknowledges the financial support by the Spanish Ministry of Education and Science through Research Grants SEJ2004-03276, SEJ2005-08783-C04-03 and SEJ2007-60671 and also by the Generalitat de Catalunya through Research Grant 2005SGR-213, the XREPP and the The Barcelona GSE Research Network.

We appreciate the comments of Dolors Berga, Matthew Ellman, Moshe Justman, Miguel Angel Lopez-Garcia, Dario Maldonado, Francois Maniquet, Dirk Schindler and seminar participants at Universitat Autonoma de Barcelona (Department of Business Economics), University of Girona, University of Namur and University of Pompeu Fabra. Errors remain ours.
} 


\section{Introduction}

Public intervention in the student loan market is usually motivated by the general view that the market fails to provide such loans. In other words, student credit is rationed. An illustration of this sentiment can be found in official publications such as Eurydice (1999), which reports that private banks are reluctant to offer student loans primarily because of high default rates. As a result, in many countries, governments provide banks with subsidies and/or guarantees against the risk of default. Then, banks provide student loans. However, loans offered by banks are always "pure" loans: they do not insure borrowers against the risk of a bad outcome, like dropping out of university, or being unsuccessful in the labor market.

This lack of insurance in private loans is in deep contrast with the new trend observed among loans provided by many governments. Indeed, the repayment of most of public loans is now income contingent 11 If there is demand for income contingent loans and banks do not provide them, there is a second failure of the student loan market, to wit lack of insurance.

In this paper, we propose a model that provides a rationale for these two market failures. Agents are risk averse and need to borrow in order to invest in education. They differ in ability, or probability of success, which is private information. Banks are perfectly competitive and offer menus of loan contracts that may include insurance against the eventuality of failure. The main feature of our model is that it accounts for default as a strategic decision of the agent. This allows to consider the role of ex-post moral hazard in combination with asymmetric information on the agent's type. ${ }^{2}$

Ex-post moral hazard may occur after the outcome of the investment is realized, and borrowers have incentives to default. Such incentives are conditional on the design of default rules, for which some heterogeneity is observed at the international level. For instance, La Porta et al. (1998) establish a difference in credit market development depending on whether the country is influenced by common law or by French law tradition. The difference among the two is precisely the legal protection of investors, stronger in common-law countries. Ionescu (2007) studies the implications of the change in the bankruptcy rule for student loans in the US, and shows that the choice of rule affects the default behavior of borrowers, who may default for strategic reasons under some institutional arrangements. Salmi (1999) attributes high default levels in student loans partly to

\footnotetext{
${ }^{1}$ This has been the case in countries such as Australia, New Zealand, Sweden, Canada, the UK, Thailand, Canada and, very recently, Spain. See Chapman (2005) and Chapman \& Greenaway (2006) for an international overview of ICL's. The US Department of Education also has developed an "Income Contingent Repayment Plan", whereby the monthly payments are pegged to the borrower's income, family size and total amount borrowed.

${ }^{2}$ The type of moral hazard we are referring to should not be misperceived as ad interim moral hazard, whereby investors may have incentives to reduce their efforts to succeed in their project. See, among others, Vercammen (2002) for an analysis mixing ad interim moral hazard and adverse selection in credit markets.
} 
"poor management of the loan recovery function". Bertola et al. (2006) recall that "Equilibrium models of default recognize that all debt could be repaid if the punishment were sufficiently large. In reality, punishment is even less severe than permanent exclusion from further consumption smoothing opportunities". Default penalties are modelled here as the proportion of the wage that banks can garnish when the agent defaults. In reality, the effective size of default penalties depends upon several other things such as bankruptcy norms, enforcement costs or social and psychological penalties. Our modelling strategy allows us to provide a rationale for the above mentioned observations of credit rationing and lack of insurance in the student loan market.

We obtain the following results. The interaction of ex post moral hazard and adverse selection proves fundamental in explaining credit rationing in the student loan market when default penalties are relatively soft. When default penalties are intermediate, banks offer pooling non-insuring contracts at equilibrium. If penalties for default are very large, banks are able to separate types and provide both types of agents with credit and insurance, where the most insured agents are of low ability. Despite the insurance involved in low ability agents' contract, the latter may not be accepted because, unlike at the pooling equilibrium, its terms do not involve cross-subsidization by the high ability agents.

The model can also be used to explain other stylized facts. For example, it can be shown that private loans are more likely to be offered the higher the return to education in case of success (Lochner \& Monge-Naranjo (2008)) and that the introduction of subsidies improves the case for private lending (Shen \& Ziderman (2007) show that private student loans are heavily subsidized all over the world). We also describe the necessary institutional framework for governments to be able to offer income contingent loans of the type mentioned before.

\section{Related literature}

Our work relates to two branches of literature. The first one starts with Stiglitz \& Weiss (1981) and attributes credit market failures to the asymmetric information regarding the investor's probability of success. A second strand of the literature shows that credit rationing arises endogenously when individual borrowers can default on debt (Zeira (1991) and Kehoe \& Levine (1993)).

In our opinion, the direct application of the first strand of literature to the education finance problem is not satisfactory. As we will argue below, on the one hand, the assumptions that lie at the basis of the Stiglitz \& Weiss (1981) model are inappropriate for education. On the other hand, the de Meza \& Webb (1987) model is more appropriate for the education finance problem. However, it obtains a credit market imperfection result that is characterized by overinvestment, which is also at odds with the stylised facts we want to explain. In the rest of this introduction, we make these points clear and discuss other related literature.

In Stiglitz \& Weiss (1981), projects have the same expected return but risks differ in the sense 
of a Mean Preserving Spread (MPS). Under this setting of MPS and borrowers' limited liability, the riskier investor is willing to pay a higher interest than the less risky investor. In the case of unsatisfied demand, the standard market mechanism relies on an increase of the price to clear the market. In the Stiglitz and Weiss setting however, an increase of the price of credit - the interest rate - may fail to reach this objective. Indeed, since low risk investors will drop out before high risk investors, the composition of risks changes, and the expected probability of success of an investment decreases. It may then be optimal for profit maximizing banks not to raise the interest rate and to ration credit.

A different setting based on the First Order Stochastic Dominance (FOSD) concept is used by de Meza \& Webb (1987): investors differ in terms of expected returns, with the ablest having the greatest probability of success. In contrast to Stiglitz \& Weiss (1981), the ablest investor is more willing to pay for a loan. Because of this, a market imperfection in de Meza \& Webb (1987) implies overinvestment rather than credit rationing. Indeed, if separation of types is impossible, bad types do not drive out good types as in Stiglitz \& Weiss (1981), but instead both types are pooled. If the low ability agent's investment is inefficient, asymmetric information thus implies that too many projects are financed ${ }^{3}$

In the economics of education literature it is usually assumed that high ability students face larger expected returns from investing in education. Moreover, their probability of success is also larger. Of the two models discussed above, the de Meza \& Webb (1987) framework, with its First Order Stochastic Dominance concept, thus seems much more appropriate than Stiglitz \& Weiss (1981) to describe the conditions of the market for student loans. Strikingly, however, only the latter can produce credit rationing.

Despite its obvious flaws in the context of student loans, the setting proposed by Stiglitz \& Weiss (1981) has been applied to explain the absence of purely private student loans. For example, Barr (2001) notes that both the average and the variance of the rate of return of the education investment vary across professions. The average income of doctors is high, and the variance low. In contrast, the average income of actors is low, and the variance, large. It may then be considered sensible to adopt the Mean Preserving Spread setting and conclude that adverse selection arises because the student has private information about her career choice. Yet, career choices are easily observed. Charging different prices for different diplomas is, far from "introducing slavery by the back door" (in the words of Barr), a common practice in most countries. If the information about career choice cannot be hidden, adverse selection cannot take place.

Common wisdom perseveres, however. Canton \& Blom (2004), in another of numerous examples, also argue that market failure in the student loan market is due to adverse selection. In their words:

\footnotetext{
${ }^{3}$ See Boadway \& Keen 2004 for a unifying analysis of the two models.
} 
"Students who are more likely not to be able to repay their loan, the "bad risks", would be more interested in applying for a student loan than the "good risks". Banks therefore charge a risk premium on top of the risk-free interest rate. This further discourages high ability students from applying for a bank loan, as it entails that the high ability students cross-subsidize the low ability students. Adverse selection would further drive up the risk premium, possibly turning the credit system unsustainable over time." More recently, Jacobs \& van Wijnbergen (2007) analyze optimal financing of risky higher education, applying explicitly the Stiglitz \& Weiss (1981) setting.

Notwithstanding, as mentioned before, a second strand of the literature, starting with Zeira (1991) and Kehoe \& Levine (1993), show that credit rationing arises endogenously when individual borrowers can default on debt in macroeconomic models with complete information. In the particular context of human capital investments, the impact of endogeneous borrowing limits on growth has been pointed out by Tsiddon (1992) and more recently de la Croix \& Michel (2007). Finally, Fender \& Wang (2003) studies the general equilibrium effects of this kind of constraints and evaluates the welfare effects of different educational policies such as subsidies or publicly provided education.

By considering simultaneously asymmetric information and ex-post moral hazard, our work brings together these two branches of the literature. This allows us to analyze a number of stylized facts such as the two aforementioned market failures (credit rationing and lack of insurance), the capacity of subsidies to bring about student lending, the role of expected earnings, or the fact that, unlike banks, governments are able to provide the same income contingent loan contract to all students.

The rest of the paper is organized as follows. In Section 2, we present the model. In Section 3, we characterize the equilibrium outcomes corresponding to different levels of the default penalty that we label soft, intermediate, larger and largest. Section 4 provides some additional, comparative static results and Section 5 concludes.

\section{The model}

There is a population of unskilled agents of measure 1. At the beginning of the period, agents decide whether to invest in higher education or not. This investment is risky and has two possible outcomes $\sigma=\{f, s\}$, where $f$ stands for failure and $s$ for success. In case of success, an agent becomes skilled and obtains an exogeneous wage $w_{s}$. In case of failure, she remains unskilled and receives the same wage as an agent who chose not to study, $w_{f}$. For simplicity, we assume that the outcome of the investment is common knowledge. Agents differ in ability $a \in\{l, h\}$, which affects their probability of success: $p_{a}$ with $0<p_{l}<p_{h}<1$. Although this probability is private 
information, the share of agents of high $(h)$ ability in the population, $\lambda$, is common knowledge.

Investments in higher education are costly. We denote these costs, which comprise tuition fees and living expenditures, by $F$. Agents need to borrow in order to finance $F$. If they do not accept any loan contract, they remain unskilled and earn with certainty a wage $w_{f}$.

The credit market consists of a set of profit maximizing banks offering loans of size $F$, competing à la Bertrand. A student loan contract is a pair of interest rates $\left(r_{s}, r_{f}\right) \in \mathbb{R}^{2}$, where $r_{s}$ and $r_{f}$ are the interest rates charged respectively in case of success and failure. The contingency of the interest rate to the state of nature allows the loan contract to provide agents with some insurance, by setting $r_{s}>r_{f}$. Note that this is precisely what publicly managed income contingent loan programs do. In particular, it is often the case in these programs that $r_{s}>r_{f}=0$.

Banks may offer more than one contract, or no contract at all. The banks' strategy is thus a set, or menu of contracts. When facing the menu of contracts offered by banks, unskilled agents decide whether to accept one of them or refuse all of them. However, accepting one contract does not necessarily imply that it will be respected.

Indeed, a particularity of our model is that banks are subject to ex-post moral hazard from borrowers: once the outcome of the investment in education is realized, agents decide whether to repay the loan or to default by weighting the gain in resources from non repayment against the punishment for default. In this paper, as Chen (2005) and Lochner \& Monge-Naranjo (2008), we model this level of responsibility as a penalty amount incurred by the defaulting borrower. In particular, this penalty is defined as the garnishment by the bank of a share $g \in[0 ; 1)$ of the wage, $w_{\sigma}$. This is a simplifying assumption that reflects the fact that the bank cannot expropriate those who default. However, as Lochner \& Monge-Naranjo (2008) points out, "Even if human capital cannot be directly repossessed by lenders, creditors can punish defaulting borrowers in a number of ways (e.g. lowering credit scores, seizing assets, garnisheeing a fraction of labor earnings), which tend to have a greater impact on debtors with higher post-school earnings." This justifies the assumption that the penalty is proportional to earnings. Moreover, in many countries, defaulters can indeed be subject to the garnishment of up to a certain proportion of the wage. In the case of the Federal Family Educational Loan (FFEL), in the USA, the garnishment rate is set at a maximum of $15 \%$. In other countries, such as Spain, the scheme of default penalties is more complex, following a graduated scale and with exemptions. On the other hand, personal bankruptcy laws sometimes allow to escape the penalty, further protecting defaulters.

All in all, the legal system provides the borrower with some insurance against failure, even if the contract designed by the bank does not include such insurance. Later, we will refer to a non-insuring contract when the bank does not provide any level of insurance that is above the one guaranteed by law. 
Agents are risk averse and care for consumption over their productive life $Y \in \mathbb{R}^{+}$. The utility function is continuous, strictly increasing and strictly concave and is denoted $U(\cdot): \mathbb{R}^{+} \rightarrow \mathbb{R}^{+}$. The expected utility of an individual who invests in education and has probability of success $p_{a}$ is denoted

$$
E U\left(p_{a}, Y_{s}, Y_{f}\right)=p_{a} U\left(Y_{s}\right)+\left(1-p_{a}\right) U\left(Y_{f}\right)
$$

where $Y_{s}$ and $Y_{f}$ are consumption levels contingent respectively on success and failure. These consumption levels depend both on the accepted loan contract, and on the penalty the borrower endures in case of default. Indifference curves of the two types of agent have negative slopes and satisfy the single-crossing condition. Indeed, for all $\left(Y_{f}, Y_{s}\right) \in \mathbb{R}_{+}^{2},\left.\frac{d Y_{s}}{d Y_{f}}\right|_{E U\left(p_{a}, Y_{f}, Y_{s}\right)=U}=-\frac{1-p_{a}}{p_{a}} \frac{U^{\prime}\left(Y_{f}\right)}{U^{\prime}\left(Y_{s}\right)}$, where $U$ is constant. Since $-\frac{1-p_{a}}{p_{a}}$ is increasing in $p_{a},\left.\frac{d Y_{s}}{d Y_{f}}\right|_{E U\left(p_{h}, Y_{f}, Y_{s}\right)=U}>\left.\frac{d Y_{s}}{d Y_{f}}\right|_{E U\left(p_{l}, Y_{f}, Y_{s}\right)=U^{\prime}}$ for all $U, U^{\prime} \in \mathbb{R}^{+}$.

Banks get their revenue from loan repayments and/or garnishment of wages, and suffer the costs of borrowing the funds on the international market at the risk-free interest rate $i$.

The timing of the game is the following:

1. Nature draws the type of an unskilled agent. He will be of high ability $(h)$ with probability $\lambda$, otherwise her ability is low $(l)$.

2. Banks offer a menu of student loan contracts to the agent.

3. The agent observes the menu of contracts and decides, given her ability, whether to accept one of the loan contracts or refuse all of them and remain unskilled. If banks offer no contract, the agent remains unskilled and the game ends.

4. If the agent accepts one contract, the investment in higher education materializes and, accounting for the agent's ability, nature realizes the outcome $(\sigma \in\{f, s\})$ of the investment.

5. The agent pays the loan or defaults, in which case banks recover the loan up to the legal limit $g w_{\sigma}$.

\subsection{Equilibrium}

The equilibrium concept is Subgame Perfect Nash Equilibrium (SPNE) in pure strategies. ${ }^{4}$ As described in the timing of the game, a strategy profile gathers three strategies: banks' offer of the

\footnotetext{
${ }^{4}$ Even though there are two types and information is asymmetric, the equilibrium concept does not need to rely on Bayesian expectations. Indeed, the uninformed players - banks - do not need to formulate beliefs about which type will take a contract. Because they play first, the contracts they design allow them to anticipate with certainty what type(s) they are going to face for each contract offered. For further discussion of this issue, see Mas-Colell (1995) Chapter 13.
} 
menu of contracts, agents' acceptance of one of the contracts or refusal of all of them, and, finally, once the outcome is realized and in case agents have subscribed to one contract, agents' compliance with the contract or default. To be an SPNE, a strategy profile must be such that

1. At stage 5 , borrowers maximize utility by defaulting if $R_{\sigma} F>g w_{\sigma}$.

2. At stage 3, an unskilled agent accepts the contract that provides her with the highest level of utility, provided the latter is higher than the one obtained by remaining unskilled. Otherwise, she refuses all contracts.

3. At stage 2, banks offer a menu of student loan contracts that maximize expected profits. Because of Bertrand competition, the highest value for expected profits is zero, so that at equilibrium, every contract $\left(r_{f}, r_{s}\right)$ in the menu must be such that

$$
\begin{aligned}
E \Pi\left(q, r_{f}, r_{s}\right) & =q \min \left(R_{s} F, g w_{s}\right)+(1-q) \min \left(R_{f} F, g w_{f}\right)-I F \\
& =0
\end{aligned}
$$

where $q \in[0 ; 1]$ is the expected probability of success of the agents for whom the contract is intended.

The menu of contracts will be empty at equilibrium if all possible loan contracts provide the bank with strictly negative profits.

If the menu is composed of two contracts, and banks anticipate that each of them will be selected by a different type of agent, the equilibrium is separating and $q=p_{h}$ for the contract selected by high ability agents, while $q=p_{l}$ for the contract selected by low ability agents.

Finally, the menu may be a singleton, and two scenarios emerge. Either banks anticipate that both types will accept the contract, and $q=p_{p} \equiv \lambda h+(1-\lambda) l$ (the equilibrium involves pooling both types). Or, alternatively, banks anticipate that only one type will accept it. If this is the case, since the expected gain from investing in higher education is higher for the high ability agent, she will be the one who takes such a contract.

At equilibrium, then, student consumption levels in outcome $\sigma \in\{f, s\}$ are

$$
Y_{\sigma}=\max \left\{w_{\sigma}-R_{\sigma} F,(1-g) w_{\sigma}\right\}
$$

for $R_{\sigma} \equiv 1+r_{\sigma}$. Conversely, banks' profits under outcome $\sigma \in\{f, s\}$ write

$$
\Pi_{\sigma}=\min \left\{R_{\sigma} F, g w_{\sigma}\right\}-I F,
$$

where $I \equiv 1+i$. 


\subsection{Graphical analysis}

In order to analyze under which conditions the various types of equilibria will emerge, it will prove convenient to represent all players' strategies in the space of consumption levels of agents in case of failure and success $\left(Y_{f}, Y_{s}\right)$, as illustrated in Figure 1. Such a space can be divided into two subspaces relative to the two strategies that agents can play at stage 5: repay or default. Let us define in this space the set of allocations such that default does not occur:

Definition 1 The default-proof space, $D P(g)$ is the set of consumption bundles $\left(Y_{f}, Y_{s}\right)$ such that for all $\sigma \in\{f, s\}, w_{\sigma}-R_{\sigma} F \geq(1-g) w_{\sigma}$.

In $D P(g), Y_{\sigma}=w_{\sigma}-R_{\sigma} F \geq(1-g) w_{\sigma}$ for all $\sigma \in\{f, s\}$, while outside $D P(g)$, there exists at least one outcome $\sigma \in\{f, s\}$ such that $Y_{\sigma}=(1-g) w_{\sigma}>w_{\sigma}-R_{\sigma} F$. This implies that, in the space of consumption levels, one can establish a one to one relation between loan contracts $\left(r_{f}, r_{s}\right)$ and consumption levels $\left(Y_{f}, Y_{s}\right)$ only inside $D P(g)$. In other words, students can credibly commit to pay interest rates $\left(r_{f}, r_{s}\right)$ inside $D P(g)$. Out of $D P(g)$, a contract is not respected, in which case banks are legally allowed to garnish $g w_{\sigma}$ and consumption is in fact $Y_{\sigma}=(1-g) w_{\sigma}$. Such consumption bundles are located on the boundaries of $D P(g)$. This is what happens if contracts are non-insuring.

Definition 2 A non-insuring contract is a contract such that, in case of failure, $R_{f} F>g w_{f}$ so that a borrower has the lowest possible level of consumption in this state of the world: $Y_{f}=(1-g) w_{f}$.

Note that a non-insuring contract can be viewed as a pure loan contract, with $R=R_{f}=R_{s}$, where banks, anticipating that borrowers default in case of failure, adjust the interest rate in order to avoid losses 5

Let us now represent, in the space $\left(Y_{f}, Y_{s}\right)$, the set of loan contracts that provide, for a given expected probability of success $q$, zero expected profits. Since $Y_{\sigma}+\Pi_{\sigma}=w_{\sigma}-I F, E \Pi\left(q, r_{f}, r_{s}\right)$ can be rewritten as

$$
E \Pi\left(q, Y_{f}, Y_{s}\right)=q\left(w_{s}-Y_{s}\right)+(1-q)\left(w_{f}-Y_{f}\right)-I F
$$

Equation (3) allows us to define the zero profit locus in terms of combinations of consumption bundles in case of failure and success $\left(Y_{f}, Y_{s}\right)$.

\footnotetext{
${ }^{5}$ For zero expected profits and a probability of success $q$, this interest rate is $R=\frac{I F-(1-q) g w_{f}}{q F}$. Indeed, banks' expected profits are then equal to $q \frac{I F-(1-q) g w_{f}}{q F} F+(1-q) g w_{f}-I F=0$.
} 


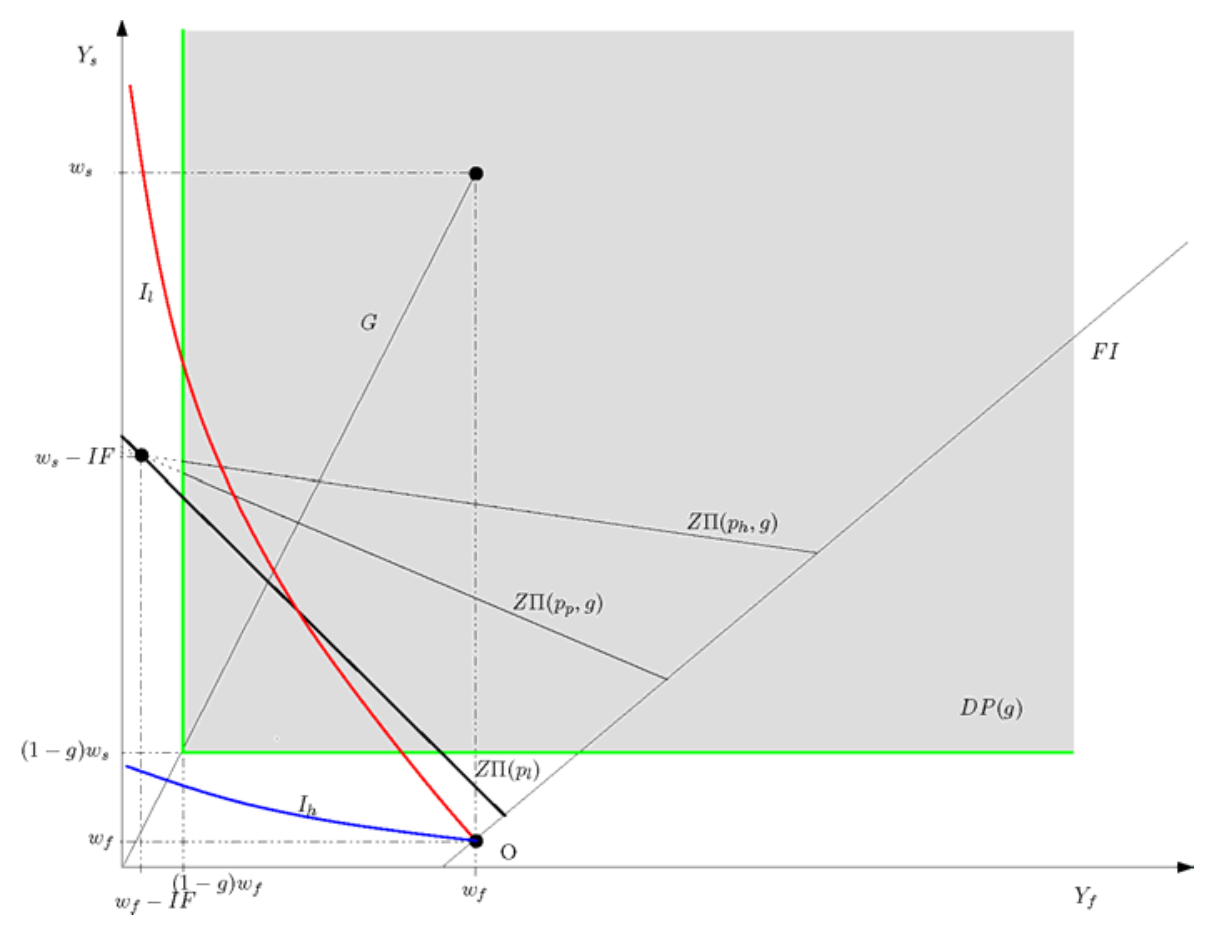

Figure 1: Basic elements of the model

Definition $3 Z \Pi(q, g)$ is the set of consumption bundles $\left(Y_{f}, Y_{s}\right)$ in DP $(g)$ such that, for a probability of success $q$, banks make zero expected profits:

$$
Y_{s}=\left[w_{s}-w_{f}+\frac{w_{f}-I F}{q}\right]-\frac{1-q}{q} Y_{f}
$$

For convenience, we will often refer to $Z \Pi(q) \equiv Z \Pi(q, 1)$, the zero-profit locus when all contracts are immune to ex-post moral hazard. This will allow us to discuss and compare these loci in the largest possible set of consumption bundles. Indeed, when $g=1, Y_{\sigma}=\max \left\{w_{\sigma}-R_{\sigma} F, 0\right\}$, so that the default proof space is $\mathbb{R}_{+}^{2}$. In Figure 1 , as $g$ decreases (penalties become softer) the defaultproof space shrinks, its origin moving along $G$ - the set of consumption bundles $\left(Y_{f}, Y_{s}\right)$ such that $Y_{s}=\left(w_{s} / w_{f}\right) Y_{f}$ - towards $\left(w_{f}, w_{s}\right)$. Figure 1 also depicts, in the $\left(Y_{f}, Y_{s}\right)$ space, the default-proof space and the zero profit loci: $Z \Pi\left(p_{l}\right)$, when contracts are accepted only by low ability agents; $Z \Pi\left(p_{p}\right)$, for contracts that pool together high and low ability agents; and $Z \Pi\left(p_{h}\right)$, for contracts that separate high ability agents. Clearly, the slope of a zero profit locus is given by $-(1-q) / q$. Thus, since $p_{l}<p_{p}<p_{h}, Z \Pi\left(p_{h}\right)$ is the flattest of these loci, followed by $Z \Pi\left(p_{p}\right)$ and, finally, $Z \Pi\left(p_{l}\right)$, the steepest one. Also, zero profit loci cross at $\left(Y_{f}, Y_{s}\right)=\left(w_{f}-I F, w_{s}-I F\right)$. Finally, note that bundles below [above] $Z \Pi(\cdot)$ yield negative [positive] profits. Still in this figure, $F I$ is the certainty or full insurance line, characterized by the set of consumption bundles $\left(Y_{f}, Y_{s}\right)$ such that 
$Y_{f}=Y_{s}$.

Finally, point $O$ in Figure 1 represents the outside option of refusing all contracts and remaining unskilled $\left(w_{f}, w_{f}\right)$. Also, $I_{l}\left[I_{h}\right]$ is the set of consumption bundles $\left(Y_{f}, Y_{s}\right)$ such that $E U\left(p_{l}, Y_{f}, Y_{s}\right)=$ $U\left(w_{f}\right)\left[E U\left(p_{h}, Y_{f}, Y_{s}\right)=U\left(w_{f}\right)\right]$, i.e., the low [high] ability agent's indifference curve for a utility level obtained at the outside option.

\section{Characterization of the equilibria}

In this section, we solve the game for all values of $g$. The first subsection deals with "soft" default penalties (low $g$ ). We show that the interaction between ex-post moral hazard and adverse selection yields a complete market failure, where no loans are offered. The second subsection studies intermediate default penalties (intermediate $g$ ). In such a case, the market equilibrium is characterized by pooling contracts where no insurance takes place. The third subsection presents the conditions under which no equilibrium exists. The last subsection discusses the case where default penalties are largest, which results in a separating equilibrium.

\subsection{Low default penalties}

When default penalties are sufficiently low, the best strategy at the last stage is for agents to default. Yet, since penalties are low, banks' revenues yield negative profits, so they will not offer any contract. This is the intuition behind credit rationing in our model. As default penalties $g$ increase, a market will eventually emerge. We discuss here the upper bound on default penalties such that credit rationing exists. We thus start from $g=0$ and gradually increase it. Trivially, if $g=0$, the borrower has the choice between repaying her loan or default and suffer no penalty at all. Conversely, the bank does not receive any payments and makes losses. As $g$ increases, some contracts become exempt of default, but they involve very small interest rates since penalties are still very low and agents prefer otherwise to default. Those interest rates are so small that, even if they were taken high ability agents, they would not be able to cover the risk-free interest rate $i$, and thus would still yield negative profits. Hence, the market does not exist.

As $g$ reaches $g_{0}^{h}$, which is defined as the lowest $g$ such that $Z \Pi\left(p_{h}, g\right)$ is non-empty, banks can now offer contracts that are exempt of default and that would, if only high ability agents took them, yield non-negative profits. However, a contract corresponding to the singleton $Z \Pi\left(p_{h}, g_{0}^{h}\right)$, i.e. $Z \Pi\left(p_{h}\right) \cap G$ would be preferred by low ability agents to the outside option. ${ }^{6}$ Therefore, expected

\footnotetext{
${ }^{6}$ This is always true given the following assumption, which, although not necessary proves useful for the presentation of results. Let $\left(\overline{\bar{Y}}_{f}, \overline{\bar{Y}}_{s}\right)$ be the point where $I_{l}$ intersects $Z \Pi\left(p_{h}\right)$. We assume $\overline{\bar{Y}}_{s} \geq\left(w_{s} / w_{f}\right) \overline{\bar{Y}}_{f}$, i.e. $I_{l} \cap Z \Pi\left(p_{h}\right)$ lies to the left of $G$. The implications of relaxing this assumption are available upon request.
} 


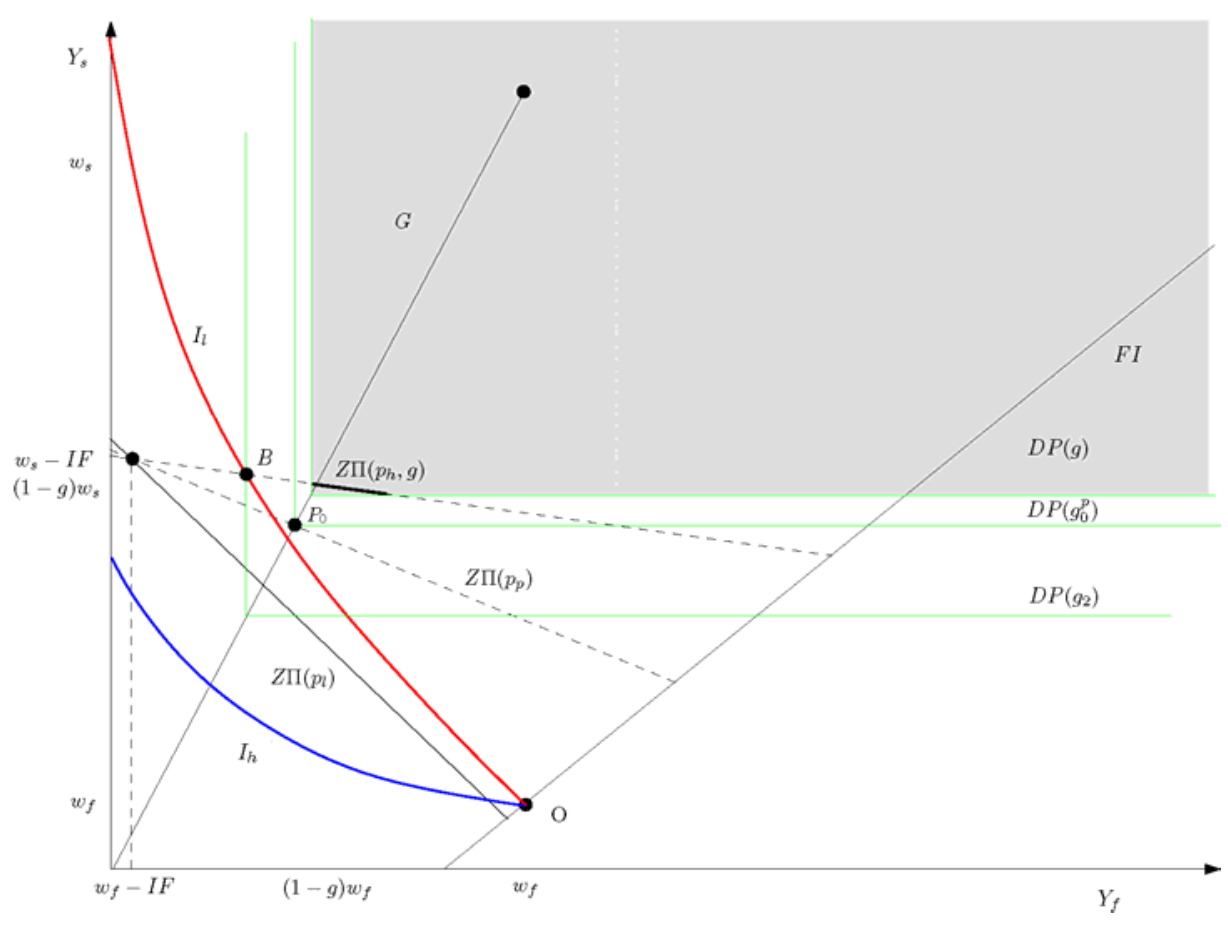

Figure 2: Credit rationing equilibrium $\left(g<g_{0}^{p}=\min \left\{g_{0}^{p}, g_{2}\right\}\right)$

profits would still be negative, and banks would still refuse to offer loan contracts.

Definition 4 Let $g_{2}$ be the minimum $g$ such that $I_{l} \cap Z \Pi\left(p_{h}\right) \equiv B \in D P(g)$.

The default-proof space $D P\left(g_{2}\right)$ is illustrated in Figure 2 .

When $g$ reaches $g_{2}$, banks are able to offer a contract on $Z \Pi\left(p_{h}, g_{2}\right)$ that only high ability agents will pick, since, as stated in Definition 4 , this contract, which corresponds to point $B$, provides low ability agents with the same utility level than the outside option. Banks are therefore no longer making losses and a market for student loans emerges.

Note that point $B$ represents the bundle on $Z \Pi\left(p_{h}, g_{2}\right)$ which is the farthest from the full insurance line. In other words, the contract that corresponds to $B$ is the riskiest default-proof contract on $Z \Pi\left(p_{h}, g_{2}\right)$. For only high ability agents to accept a contract, banks indeed have to offer a contract that yields a low consumption level in case of failure in order to deter low ability agents, who face a higher probability of failure.

The threshold $g_{2}$ may however be very large.7 Then, banks might want to look for other

\footnotetext{
${ }^{7}$ This is more likely, on the one hand, the lower the level of risk aversion and on the other, the higher the probability of success of high ability agents. To see why, keep in mind that the slope of $Z \Pi(p)$ equals $-(1-p) / p$, which is increasing in $p$.
} 
opportunities of offering contracts than trying to specifically target high ability agents. For instance, even though $g$ were lower than $g_{2}$, it might be sufficiently high so that contracts that yield zero profits when both types accept them become default-proof: $Z \Pi\left(p_{p}, g\right)$ is non-empty. The level of $g$ that is just sufficient to allow banks to offer a default-proof contract that yields non-negative profits when both types pick it $\left(P_{0}\right.$ in Figure 2$)$ is noted $g_{0}^{p}$. It is formally defined in Definition 5 and depicted in Figure $2^{8}$

Definition 5 Let $g_{0}^{p}$ be the minimumg such that $Z \Pi\left(p_{p}, g\right)$ is non-empty. It is such that $Z \Pi\left(p_{p}, g_{0}^{p}\right)=$ $P_{0} \equiv Z \Pi\left(p_{p}\right) \cap G$

Summing up, credit rationing, i.e. banks do not offer any student loans, exists as long as banks are unable to offer loans that borrowers can credibly commit to repay. More precisely, credit rationing exists as long as default penalties are not sufficient to allow banks either to screen borrowers $\left(g<g_{2}\right)$ or to pool them $\left(g<g_{0}^{p}\right)$. This result is stated formally in the following proposition.

Proposition 1 Credit rationing exists at equilibrium if and only if $0 \leq g<\min \left\{g_{0}^{p}, g_{2}\right\}$.

The preceding discussion actually proved Proposition 1. Indeed, we have shown in the first part of the discussion that low values of $g<\min \left\{g_{0}^{p}, g_{2}\right\}$ imply that banks do not offer loans at equilibrium since such an offer would incur losses. The other implication, that credit rationing exists at equilibrium only if $g<\min \left\{g_{0}^{p}, g_{2}\right\}$, was proved by showing that for $g \geq \min \left\{g_{0}^{p}, g_{2}\right\}$, there exists a deviation from credit rationing, so that the latter cannot be an equilibrium.

Figure 2 depicts to the credit rationing equilibrium when $\min \left\{g_{0}^{p}, g_{2}\right\}=g_{0}^{p}$. This market failure can be solved rather trivially if we can provide the information that allows to identify high ability individuals provided that $g$ is large enough to rule out default by these individuals. This shows that banks refrain from offering loan contracts when default penalties are low because of the interaction between ex-post moral hazard and adverse selection. In the following subsection we explore the consequences of increasing $g$ on the equilibrium.

\subsection{Intermediate default penalties}

As default penalties increase further, more contracts become default-proof $(D P(g)$ moves down). In this subsection, we explore the possibility that a pooling equilibrium exists and show that, when it does, it involves minimum insurance on the part of banks.

\footnotetext{
${ }^{8}$ Note that $g_{0}$ is likely to be small if $1-\lambda$, the share of low ability agents in the population, is low, and if low ability agents have high chances of success. The value of $g_{0}$ is likely to be small if the position of $Z \Pi\left(p_{p}\right)$ is high, which will be the case if $p_{p} \equiv \lambda p_{h}+(1-\lambda) p_{l}$ is large.
} 


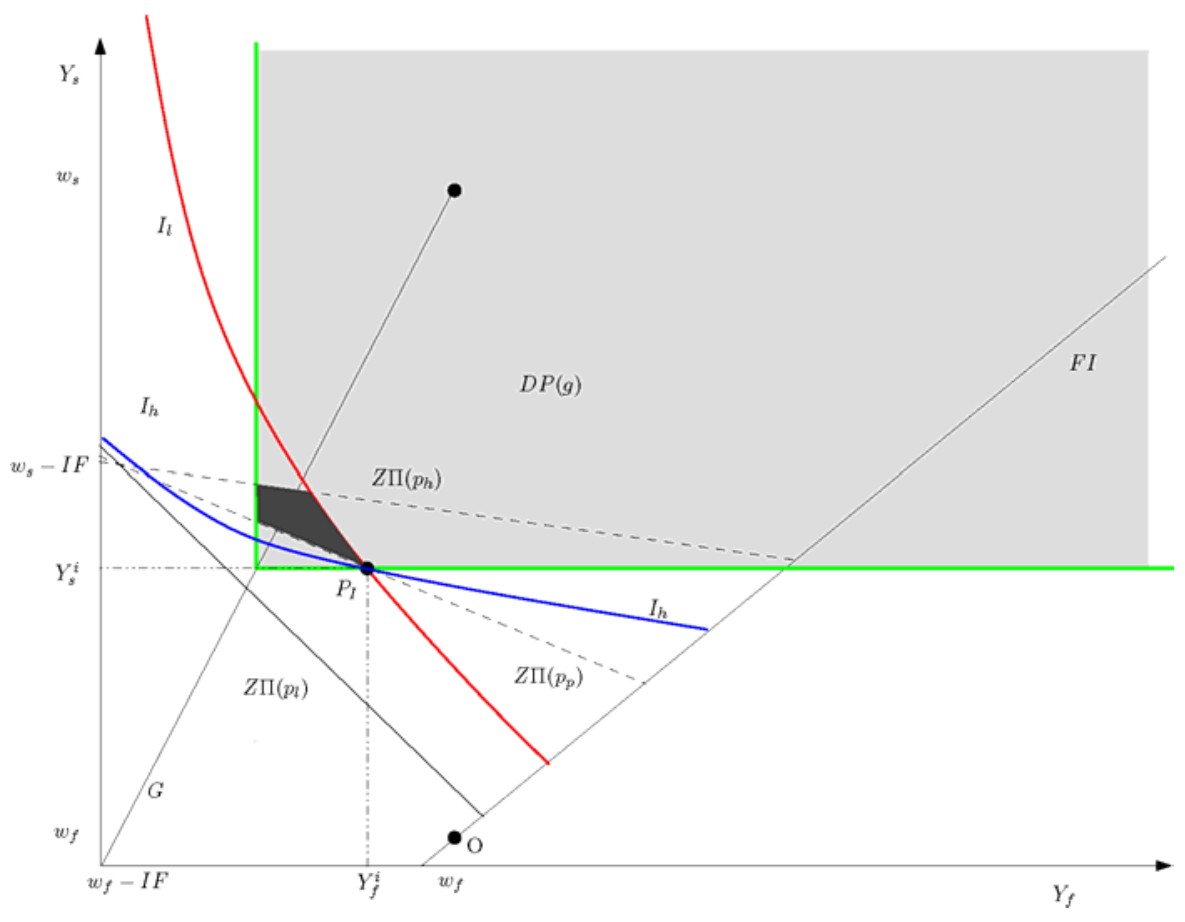

Figure 3: No insurance at the pooling equilibrium

A first condition that must be met is that $g \geq g_{0}^{p}$. This ensures that there exists at least one potential pooling contract $\left(P_{0}\right.$ in Figure 2). For the moment, assume all necessary conditions are satisfied and a pooling equilibrium exists. Lemma 1 shows that this equilibrium is always unique and non-insuring, i.e., the equilibrium contract leaves unsuccessful students with the lowest consumption level legally tolerated, $(1-g) w_{f}$.

Lemma 1 If a pooling equilibrium exists, it is unique and it is such that the contract offered by banks is non-insuring.

The formal proof of this lemma is provided in Appendix 1. Figure 3 depicts a pooling equilibrium candidate with insurance, where both types of students accept a contract that provides them with the consumption bundle $\left(Y_{f}^{i}, Y_{s}^{i}\right) \equiv P_{I}$. The shaded area represents a set of consumption bundles that have two important characteristics. On the one hand, these bundles are preferred by high ability agents to $P_{I}$, while they provide low ability agents with lower utility. On the other hand, this set of bundles lies below $Z \Pi\left(p_{h}, g\right)$. A bank offering a contract corresponding to any of these bundles will thus attract only high types and make positive profits. Since a profitable deviation exists, this candidate is not an equilibrium. In fact, the only contract on $Z \Pi\left(p_{h}, g\right)$ for which there is no profitable deviation is the non-insuring pooling contract. 
Lemma 1 provides an explanation for the lack of insurance in student loans offered by private banks, which is one of the stylised facts we wanted to analyse. Note that even though banks do not provide any insurance, borrowers are insured by the legal system. As default penalties increase, the non-insuring contract becomes less attractive because legal insurance is reduced. Then, a pooling equilibrium is less likely. Let us thus now study the exact conditions under which pooling noninsuring contracts are not offered at equilibrium.

First, as we have just mentioned, as the law on default gets tougher, the "safety net" consumption level in case of failure $(1-g) w_{f}$ eventually becomes so low that the pooling contract is no longer preferred by low ability agents to the outside option. The threshold $g_{1}$ formally defines the level of $g$ at which a low ability agent is indifferent between the outside option and the non-insuring, pooling contract. Let $\left(\bar{Y}_{f}, \bar{Y}_{s}\right) \equiv A$ be the point where $I_{l}$ intersects $Z \Pi\left(p_{p}\right)$ (see Figure 4$){ }^{9}$

Definition 6 The threshold $g_{1}$ is such that

- if $\left(\bar{Y}_{f}, \bar{Y}_{s}\right)$ exists and $\bar{Y}_{s} \geq\left(w_{s} / w_{f}\right) \bar{Y}_{f}, g_{1}=\min g$ such that $\left(\bar{Y}_{f}, \bar{Y}_{s}\right) \in \operatorname{DP}(g)$,

- if $\left(\bar{Y}_{f}, \bar{Y}_{s}\right)$ exists and $\bar{Y}_{s}<\left(w_{s} / w_{f}\right) \bar{Y}_{f}, g_{1}=g_{0}^{p}$

- if $\left(\bar{Y}_{f}, \bar{Y}_{s}\right)$ does not exist, $g_{1}=1$.

From the discussion above, $g<g_{1}$ is necessary for a pooling equilibrium. Note that $g_{1} \geq g_{0}^{p}$ in any case, which will prove useful in the discussion of Proposition 2.

A second reason why pooling may not exist is that banks might find it profitable to deviate from the pooling non-insuring contract to offer another pooling contract that provides more insurance and yields positive profits. This can happen if banks are able to find a contract that is attractive to all agents and yields positive profits. Graphically, this can only be the case if the high ability agents' indifference curve that goes through the pooling non-insuring contract is steeper than $Z \Pi\left(p_{p}\right)$. Let now $\left(\tilde{Y}_{f}, \tilde{Y}_{s}\right) \equiv A^{\prime}$ be the point on $Z \Pi\left(p_{p}\right)$ that is most preferred by a high ability type (see Figure 4).

Definition 7 The threshold $g_{1}^{\prime}$ is such that

- if $\tilde{Y}_{s} \geqslant\left(w_{s} / w_{f}\right) \tilde{Y}_{f}, g_{1}^{\prime}=\min g$ such that $\left(\tilde{Y}_{f}, \tilde{Y}_{s}\right) \in D P(g)$

- if $\tilde{Y}_{s}<\left(w_{s} / w_{f}\right) \tilde{Y}_{f}, g_{1}=g_{0}^{p}$.

\footnotetext{
${ }^{9}$ Note that $\left(\bar{Y}_{f}, \bar{Y}_{s}\right)$ may not exist because the outside option may provide higher consumption levels in both states of the world than the potential full insurance pooling contract. Since the slope of $I_{l}$ is strictly larger than that of $Z \Pi\left(p_{p}\right)$, these two loci can never cross in this case.
} 


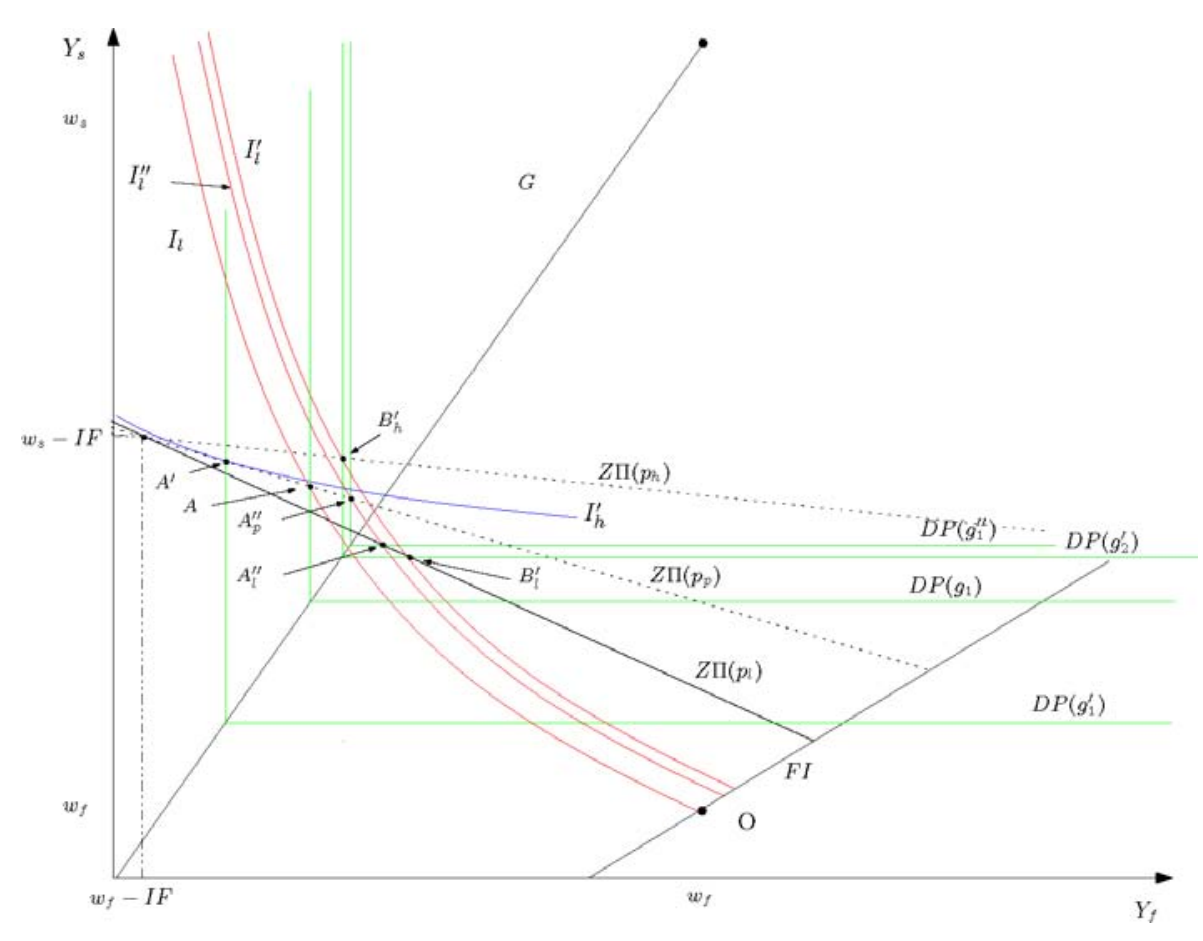

Figure 4: Illustration of $g_{1}, g_{1}^{\prime}, g_{1}^{\prime \prime}$ and $g_{2}^{\prime}$

Again, we need $g<g_{1}^{\prime}$ for a pooling equilibrium to exist. Also note that by definition $g_{1}^{\prime} \geq g_{0}^{p}$.

Finally, a pooling equilibrium may not exist if banks, instead of offering a single contract that pools both types, deviate from the pooling contract by offering a pair of separating contracts. For the contract designed for low types to make positive profits, there must exist some contract below $Z \Pi\left(p_{l}, g\right)$ that is preferred by low ability agents to the pooling non-insuring contract. The second contract banks offer is targeted to high types and must be strictly preferred by them to pooling. At the same time, this contract must be less appealing to low types than the first contract in the menu, which was designed for them 10

The lowest threshold such that such a deviation by two contracts is made possible is called $g_{1}^{\prime \prime}$ and is defined formally here. Let $\left(Y_{f}^{l *}(g), Y_{s}^{l *}(g)\right)$ be the best consumption bundle in $Z \Pi\left(p_{l}, g\right)$ for low ability agents. Let $\left(Y_{f}^{p}(g), Y_{s}^{p}(g)\right)$ be the contract that relates to the non-insuring pooling equilibrium candidate.

Definition 8 The threshold $g_{1}^{\prime \prime}$ is such that $E U\left(p_{l}, Y_{f}^{l *}\left(g_{1}^{\prime \prime}\right), Y_{s}^{l *}\left(g_{1}^{\prime \prime}\right)\right)=E U\left(p_{l}, Y_{f}^{p}\left(g_{1}^{\prime \prime}\right), Y_{s}^{p}\left(g_{1}^{\prime \prime}\right)\right)$.

\footnotetext{
${ }^{10}$ In fact, more complex deviations could also be considered in some particular cases. For instance, if the share of low ability agents is sufficiently low, banks might want to endure losses on low ability agents provided that they can compensate these losses by larger profits on high ability agents. This simply shrinks the interval of $g$ such that a pooling equilibrium exists without affecting the rest of our results.
} 
Figure 4, depicts $A_{l}^{\prime \prime} \equiv\left(Y_{f}^{l *}\left(g_{1}^{\prime \prime}\right), Y_{s}^{l *}\left(g_{1}^{\prime \prime}\right)\right)$ and $A_{p}^{\prime \prime} \equiv\left(Y_{f}^{p}\left(g_{1}^{\prime \prime}\right), Y_{s}^{p}\left(g_{1}^{\prime \prime}\right)\right)$. As before, $g<g_{1}^{\prime \prime}$ is a necessary condition for the existence of a pooling equilibrium. Appendix 2 shows that $g_{1}^{\prime \prime}$ always exists and is smaller than $I F / w_{f}$. This implies that at the pooling equilibrium, banks make losses on the students who fail and hence positive profits on those who succeed in order to break even.

Note that for $g=g_{1}^{\prime \prime}$, a low ability individual is indifferent between the pooling non-insuring contract and the contract designed for her in the deviation. For $g>g_{1}^{\prime \prime}$, the deviation contract is preferred. Since $Z \Pi\left(p_{l}, g_{0}^{p}\right)$ is empty and $Z \Pi\left(p_{l}, g_{1}^{\prime \prime}\right)$ is not, $g_{1}^{\prime \prime}>g_{0}^{p}$.

Given the number of constraints on $g$ for the existence of a pooling equilibrium and the fact that apart from strict concavity, we do not impose any assumption on preferences, it may be the case that a pooling equilibrium does not exist for any $g$. However, we have isolated two conditions on the ordering of thresholds, $C_{1}$ and $C_{1}^{\prime}$, which, together, are both necessary and sufficient for the non-emptiness of the interval of $g$ that is compatible with a pooling equilibrium.

Condition $C_{1}: g_{1}>g_{0}^{p}$.

Condition $C_{1}^{\prime}: g_{1}^{\prime}>g_{0}^{p}$.

Note that $C_{1}$ and $C_{1}^{\prime}$ respectively limit the degree of risk aversion of agents of low and high ability. This is sensible since the unique pooling equilibrium equilibrium candidate does not involve any contractual insurance.

Lemma $2 C_{1}$ and $C_{1}^{\prime}$ are necessary and sufficient conditions for $g_{0}^{p}<\min \left\{g_{1}, g_{1}^{\prime}, g_{1}^{\prime \prime}\right\}$.

To prove Lemma 2 is straightforward since $g_{1}^{\prime \prime}>g_{0}^{p}$ always. Proposition 2 provides a formal statement of the interval of $g$ which supports a pooling equilibrium.

Proposition 2 If conditions $C_{1}$ and $C_{1}^{\prime}$ are met, a pooling equilibrium exists if and only if $g_{0}^{p} \leq$ $g<\min \left\{g_{1}, g_{1}^{\prime}, g_{1}^{\prime \prime}\right\}$. Otherwise, a pooling equilibrium does not exist for any $g \in[0 ; 1]$.

Figure 5 depicts a pooling equilibrium where the upper bound on $g$ for a pooling equilibrium to exist, $\min \left\{g_{1}, g_{1}^{\prime}, g_{1}^{\prime \prime}\right\}$, equals $g_{1}^{\prime}$. It is important to note that the upper bound on $g$ for credit rationing to be an equilibrium, $\min \left\{g_{0}^{p}, g_{2}\right\}$, always equals $g_{0}^{p}$ when a pooling equilibrium exists. Indeed, then, by Proposition 2, $C_{1}$ must apply and it is easy to show that $C_{1}$ implies $g_{2}>g_{0}^{p}$. The pooling equilibrium thus emerges for values of $g$ that define default proof spaces whose origin lie on the lighter part of $G$, i.e. $g_{0}^{p} \leq g<g_{1}^{\prime \prime}$. For the level of default penalty $g$ represented in Figure 5 . the pooling contract is represented by $P^{*}$. This leaves unsuccessful agents with the lowest possible level of consumption, $(1-g) w_{f}$.

To prove this proposition, let us start by showing that when $C_{1}$ or $C_{1}^{\prime}$ is not met, pooling does not exist for any $g \in[0 ; 1]$ then. By Lemma 2, if either $C_{1}$ or $C_{1}^{\prime}$ is not met, the interval 


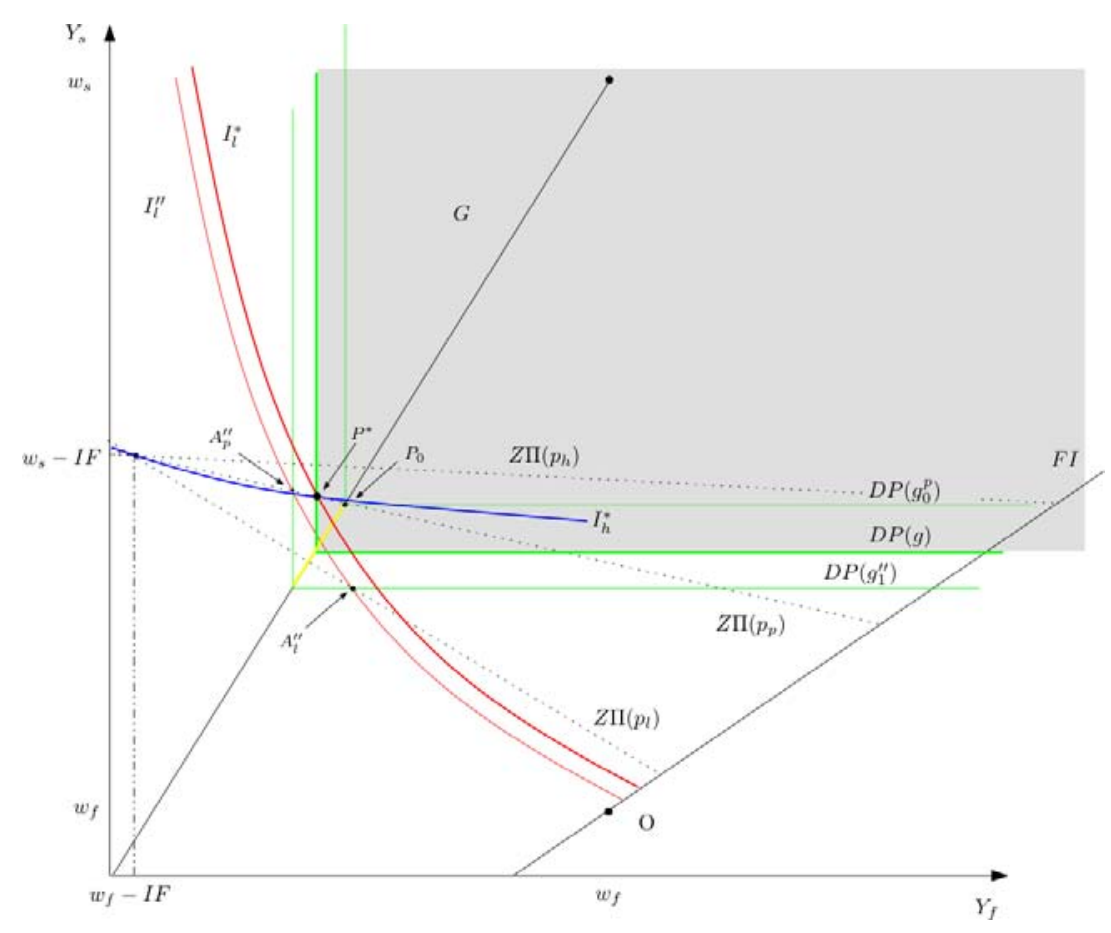

Figure 5: Pooling equilibrium $\left(\min \left\{g_{0}^{p}, g_{2}\right\}=g_{0}^{p} \leq g<g_{1}^{\prime}=\min \left\{g_{1}, g_{1}^{\prime}, g_{1}^{\prime \prime}, g_{2}\right\}\right)$

$\left[g_{0}^{p} ; \min \left\{g_{1}, g_{1}^{\prime}, g_{1}^{\prime \prime}\right\}[\right.$ is empty. We have shown before Proposition 2 that pooling could only exist within this interval. Therefore, a pooling equilibrium cannot exist for any $g \in[0 ; 1]$.

First, if $C_{1}$ is not met, then $g_{1}=g_{0}^{p}$. From Definition 6, $g_{1}=g_{0}^{p}$ if $I_{l}$ intersects $Z \Pi\left(p_{p}\right)$ to the right of $G$. However, the non-insured bundle lies on the other side of $G$. Since the slope of $I_{l}$ is larger than that of $Z \Pi\left(p_{p}\right)$, the outside option is preferred by low ability agents to the pooling equilibrium candidate.

Second, if $C_{1}^{\prime}$ is not met, then $g_{1}^{\prime}=g_{0}^{p}$. From Definition $7, g_{1}^{\prime}=g_{0}^{p}$ if $\left(\tilde{Y}_{f}, \tilde{Y}_{s}\right)$, the point on $Z \Pi\left(p_{p}\right)$ that is preferred by a high ability agent, lies to the right of $G$. Consequently, at the noninsuring, pooling bundle, which lies to the left of $G$, the high ability individual's indifference curve is steeper than the zero profit locus under pooling of types. This implies that there exist bundles that both types prefer and that yield strictly positive profits. In other words, there exist profitable deviations from the unique pooling equilibrium candidate.

The second step of the proof consists in showing that when conditions $C_{1}$ and $C_{1}^{\prime}$ are met, or equivalently $\left[g_{0}^{p} ; \min \left\{g_{1}, g_{1}^{\prime}, g_{1}^{\prime \prime}\right\}\right.$ [ is non-empty, the existence of the pooling equilibrium implies that $g_{0}^{p} \leq g<\min \left\{g_{1}, g_{1}^{\prime}, g_{1}^{\prime \prime}\right\}$. We have actually proved this in the discussion prior to the proposition. Indeed, we have shown that for values of $g$ that are outside this interval, a pooling equilibrium cannot exist. 
The third and final step of the proof consists in showing that when $\left[g_{0}^{p} ; \min \left\{g_{1}, g_{1}^{\prime}, g_{1}^{\prime \prime}\right\}[\right.$ is nonempty, $g_{0}^{p} \leq g<\min \left\{g_{1}, g_{1}^{\prime}, g_{1}^{\prime \prime}\right\}$ implies the existence of a pooling equilibrium. Let us thus show that under these conditions, there exist no profitable deviations from the pooling non-insuring equilibrium candidate. In order to do that, it will prove useful to refer to $I_{h}^{*}$ as the indifference curve of high ability agents at the equilibrium candidate.

First, agents do not want to deviate from the non-insuring contract to the outside option because $g<g_{1}$. Consider now all contracts on $I_{h}^{*}$ or below. Since $g<g_{1}^{\prime}, I_{h}^{*}$ is above $Z \Pi\left(p_{p}, g\right)$, so that any other contract strictly between $I_{h}^{*}$ and $Z \Pi\left(p_{l}, g\right)$ will make losses. Now, contracts on or below $Z \Pi\left(p_{l}, g\right)$ do not incur losses. However, since $g<g_{1}^{\prime \prime}$, those contracts provide low types with lower utility than the pooling non-insuring contract. Finally, contracts above $I_{h}^{*}$ are preferred by both types, but since $g<g_{1}^{\prime}$, those contracts make losses.

As a result, there is no profitable deviation from the pooling non-insuring equilibrium candidate. This concludes the proof of Proposition 2.

Summing up, we have seen in this subsection that the market can exist when the default penalty $g$ is not too low, and provided two conditions limiting the degree of risk aversion of agents are met. Banks will then offer a single pooling contract that involves no insurance. Of course, the legal system does provide some insurance, by limiting the amount banks can garnish in the eventuality of default. This amount that banks can garnish is not enough for banks to cover the costs of lending to those who fail since $g<g_{1}^{\prime \prime}$ (this is due to the fact that $g_{1}^{\prime \prime}<I F / w_{f}$, as shown in Appendix 2). However, by pooling individual types, banks are able to break even.

We conclude this subsection by briefly discussing the welfare effect of increasing default penalties in the interval where a pooling equilibrium emerges, $\left[g_{0}^{p} ; \min \left\{g_{1}, g_{1}^{\prime}, g_{1}^{\prime \prime}\right\}[\right.$. Since an increase in $g$ decreases the level of legal insurance, low ability agents are worse-off. However, the pooling noninsuring contract consecutive to this increase provides a higher consumption level in case of success, which leaves high ability agents better off as they have a higher probability of enjoying it.

\subsection{Larger default penalties}

In this model, there are three types of equilibrium, to wit credit rationing, pooling and separating. So far, we have identified the necessary conditions for a credit rationing equilibrium and a pooling, non-insuring equilibrium to exist. Thus, if the conditions we have provided are not met, such types of equilibria do not exist. In this subsection, we identify the conditions under which a separating equilibrium does not exist either.

A separating contract may exist if, as stated in Subsection 3.1, $g \geq g_{2}$. In this case, banks offer a unique contract which only high ability individuals accept. This contract entails so little insurance that it deters low ability agents from taking it, so that these agents remain unskilled. Conversely, 
if $g<g_{2}$, default penalties are lower, or equivalently, the degree of legal insurance is higher. This prevents banks from offering a contract that only high ability agents would pick.

A separating equilibrium may also involve two contracts. For this second kind of separating equilibrium, we need $g \geq g_{2}^{\prime}$, which we define formally here. Using the same notation as in Definition 8. $\left(Y_{f}^{l *}(g), Y_{s}^{l *}(g)\right)$ is the best consumption bundle in $Z \Pi\left(p_{l}, g\right)$ for low ability agents. Let now $\left((1-g) w_{f}, Y_{s}^{h}(g)\right)$ be the non-insuring contract in $Z \Pi\left(p_{h}, g\right)$.

Definition 9 The threshold $g_{2}^{\prime}$ is such that $E U\left(p_{l}, Y_{f}^{l *}\left(g_{2}^{\prime}\right), Y_{s}^{l *}\left(g_{2}^{\prime}\right)\right)=E U\left(p_{l},(1-g) w_{f}, Y_{s}^{h}\left(g_{2}^{\prime}\right)\right)$.

Figure 4 depicts $B_{l}^{\prime} \equiv\left(Y_{f}^{l *}\left(g_{2}^{\prime}\right), Y_{s}^{l *}\left(g_{2}^{\prime}\right)\right)$ and $B_{h}^{\prime} \equiv\left((1-g) w_{f}, Y_{s}^{h}\left(g_{2}^{\prime}\right)\right)$. Note that $g_{2}^{\prime}$ is defined in such a way that a low ability individual is indifferent between two default-proof contracts: one that provides her with the highest utility among all contracts that yield zero profits to banks when only low ability agents take them (for $g=g_{2}^{\prime}, L^{*}=B_{l}^{\prime}$ ), and another one that yields zero profits when only high ability agents take them (for $g=g_{2}^{\prime}, H^{*}=B_{h}^{\prime}$ ). Hence, $g \geq g_{2}^{\prime}$ allows, by construction, for separating contracts. As $g$ increases, the equilibrium pair of contracts, which corresponds to $L^{*}$ and $H^{*}$ become more and more desirable for both types of agents than the equilibrium at $g=g_{2}^{\prime}$, namely $B_{l}^{\prime}$ and $B_{h}^{\prime}$. Conversely, if $g<g_{2}^{\prime}$, it is not possible for banks to offer a pair of separating contracts that yield non-negative profits.

Note that since $Z \Pi\left(p_{l}, g_{0}^{p}\right)$ is empty while $Z \Pi\left(p_{l}, g_{2}^{\prime}\right)$ is not, $g_{2}^{\prime}>g_{0}^{p}$. Also, applying the same reasoning as in Appendix 2, $g_{2}^{\prime}$ always exists and is strictly larger than $g_{1}^{\prime \prime}$ and strictly smaller than $I F / w_{f}$.

In the previous subsection, we defined necessary and sufficient conditions under which a pooling equilibrium may exist. In this subsection, we also describe the necessary and sufficient condition under which, for some levels of $g$, no equilibrium exists.

Condition $C_{2}: g_{2}>g_{0}^{p}$.

Note that $C_{1}$ implies $C_{2}$, but not the other way around. Also note that if $C_{2}$ does not apply, that is, $g_{2} \leq g_{0}^{p}$, then $\min \left\{g_{2}, g_{2}^{\prime}\right\}=g_{2}$ since $g_{2}^{\prime}>g_{0}^{p}$ always.

Lemma 3 Condition $C_{2}$ is necessary and sufficient for $\min \left\{g_{1}, g_{1}^{\prime}, g_{1}^{\prime \prime}\right\}<\min \left\{g_{2}, g_{2}^{\prime}\right\}$.

To prove Lemma 3, let us first show that $C_{2}$ implies $\min \left\{g_{1}, g_{1}^{\prime}, g_{1}^{\prime \prime}\right\}<\min \left\{g_{2}, g_{2}^{\prime}\right\}$. On the one hand, $C_{2}$ implies $g_{2}>g_{1}$, and $g_{1} \geq \min \left\{g_{1}, g_{1}^{\prime}, g_{1}^{\prime \prime}\right\}$. On the other hand, $g_{2}^{\prime}>g_{1}^{\prime \prime} \geq \min \left\{g_{1}, g_{1}^{\prime}, g_{1}^{\prime \prime}\right\}$. Therefore, each element of $\left\{g_{2}, g_{2}^{\prime}\right\}$ is greater than $\min \left\{g_{1}, g_{1}^{\prime}, g_{1}^{\prime \prime}\right\}$.

Let us now prove the other implication, that $\min \left\{g_{1}, g_{1}^{\prime}, g_{1}^{\prime \prime}\right\}<\min \left\{g_{2}, g_{2}^{\prime}\right\}$ implies $C_{2}$. Assume not, then $\min \left\{g_{2}, g_{2}^{\prime}\right\}=g_{2} \leq g_{0}^{p}$. Since by definition, $g_{1}, g_{1}^{\prime}$ and $g_{1}^{\prime \prime}$ are all greater than or equal to $g_{0}^{p}$, $\min \left\{g_{1}, g_{1}^{\prime}, g_{1}^{\prime \prime}\right\} \geq g_{0}^{p}$. Then necessarily, $\min \left\{g_{2}, g_{2}^{\prime}\right\} \leq \min \left\{g_{1}, g_{1}^{\prime}, g_{1}^{\prime \prime}\right\}$ which leads to a contradiction. 
Proposition 3 If $C_{2}$ applies, the game has no equilibrium in pure strategies if $\min \left\{g_{1}, g_{1}^{\prime}, g_{1}^{\prime \prime}\right\} \leq$ $g<\min \left\{g_{2}, g_{2}^{\prime}\right\}$.

Note first that due to Lemma 3 , if condition $C_{2}$ is not met, then the interval under which no equilibrium exists is empty. This does not ensure however that an equilibrium exists for all $g \in[0 ; 1]$, since, as will be shown in the next subsection, an additional condition, $C_{S}$, is needed to ensure the existence of a separating equilibrium when $g \geq \min \left\{g_{2}, g_{2}^{\prime}\right\}$.

The absence of equilibrium in pure strategies is illustrated in Figure 4 , where $\min \left\{g_{1}, g_{1}^{\prime}, g_{1}^{\prime \prime}\right\}=g_{1}^{\prime \prime}$ and $\min \left\{g_{2}, g_{2}^{\prime}\right\}=g_{2}^{\prime}$. No equilibrium thus exists for $g_{1}^{\prime \prime}<g<g_{2}^{\prime}$ in this case.

To prove Proposition 3 , let us simply gather the information already available, keeping in mind that there are only three types of equilibrium candidates, namely credit rationing, pooling and separation. First, we know that if $g \geq \min \left\{g_{1}, g_{1}^{\prime}, g_{1}^{\prime \prime}\right\}$, neither pooling nor credit rationing can be equilibria. Second, we have shown that if $g<\min \left\{g_{2}, g_{2}^{\prime}\right\}$, a separating equilibrium cannot exist, Q.E.D..

Finally, note that the existence of a pooling equilibrium requires condition $C_{1}$, which implies $C_{2}$. In other words, if a pooling equilibrium exists, there always exists a set of larger values of $g$ such that no equilibrium exists in pure strategies.

Let us finish the characterization of the equilibria by the case where default penalties are largest, which can result in the separating equilibrium.

\subsection{Largest default penalties}

In this subsection, we show that default penalties need to be the largest for a separating equilibrium to exist. Even then, if high ability agents are too risk averse, a separating equilibrium may not exist. This stems from the fact that, as has already been discussed in the previous subsection, high ability agents are offered contracts with very little insurance at the separating equilibrium.

As we have mentioned before, a separating equilibrium can take two forms. Either it implies a pair of contracts, where each type of agent takes a different contract, or, a unique contract, accepted by only high ability agents. Low ability agents then remain unskilled. Whether one type of equilibrium or the other emerges depends on the ordering between $g_{2}$ and $g_{2}^{\prime}$, the two relevant thresholds for separation.

Consider first the case where $g_{2}<g_{2}^{\prime}$ As long as $g<g_{2}$, neither type of separating equilibrium candidate is feasible, because the separating contract targeted to high types is not default-proof, and neither is a fortiori the pair of separating contracts. When $g=g_{2}$, a separating equilibrium

\footnotetext{
${ }^{11}$ Note that a sufficient condition for this to be the case is that $Z \Pi\left(p_{l}\right)$ intersects the full insurance line below the outside option. Then, it is straightforward to see that the investment in higher education is inefficient for low ability agents: $p_{l}\left(w_{s}-w_{f}\right)<I F$.
} 
may exist. It is such that banks offer the most preferred contract by high types among those that 1) provide less utility to low types than the outside option and 2) make zero profits, i.e. belong to $Z \Pi\left(p_{h}, g_{2}\right)$. This contract corresponds to $B$. The additional condition for this contract to yield a separating equilibrium is that high ability agents must prefer $B$ to their preferred bundle on $Z \Pi\left(p_{p}, g_{2}\right)$. For convenience, we state this condition in the following terms: high ability agents must prefer $B$ to $A^{\prime}$, their favorite bundle on $Z \Pi\left(p_{p}\right) 12$ If this condition is met, then as $g$ increases, the equilibrium contract remains unchanged, because this does not allow banks to offer a new contract that would improve high ability agents' utility. Also, even though $g$ may become larger than $g_{2}^{\prime}$, and a pair of separating contracts would become default-proof, the contract designed to low ability agents would always provide them with lower utility than the outside option. This deviating pair of contracts would thus not attract neither the low nor the high ability agents.

Consider now the second case, where $g_{2}^{\prime}<g_{2}$. As long as $g<g_{2}^{\prime}$, neither type of separating equilibrium candidate is feasible. When $g=g_{2}^{\prime}$, a pair of separating contracts become default-proof. The contract aimed at attracting low ability agents corresponds to $H^{*}=\left(Y_{f}^{l *}\left(g_{2}^{\prime}\right), Y_{s}^{l *}\left(g_{2}^{\prime}\right)\right) \equiv B_{l}^{\prime}$ (see Figures 4 and 6), the most preferred bundle by low types on $Z \Pi\left(p_{l}, g_{2}^{\prime}\right)$. The second contract is, similarly to the first case, the most preferred by high types among those contracts that 1) provide less utility to low types than $B_{l}^{\prime}$ and 2) make zero profits, i.e. belong to $Z \Pi\left(p_{h}, g_{2}^{\prime}\right)$. Again, for this to be an equilibrium, we need a condition on high ability agents' preferences, namely that high ability agents prefer allocation $B_{h}^{\prime}$ to any allocation on $Z \Pi\left(p_{p}, g_{2}\right)$. In contrast, if this is not the case, banks will be able to deviate from this separating equilibrium candidate by offering a contract that will attract both types while making positive profits.

Contrary to the case where $g_{2}<g_{2}^{\prime}$, the equilibrium pair of contracts evolves, though the nature of the equilibrium remains unchanged. Indeed, $B_{l}^{\prime}$ moves along $Z \Pi\left(p_{l}\right)$ towards $F I$, the full insurance line, as $g$ increases. Recall that at the pooling equilibrium, the legal system limited the level of risk in the contract: the upper bound on $R_{f} F, g w_{f}$ is binding at equilibrium. In contrast, in the present case, default penalties limit the contract's level of insurance: $g w_{s}$, the upper bound on $R_{s} F$, is binding for the low type at equilibrium. Then, while a higher $g$ allows to increase the low ability agents' insurance, and therefore her utility, high ability agents also benefit from this increase in the severity of default penalties. The reason thereof is that less risky contracts are now needed to deter low ability agents from leaving their highly insured contract. Finally, increasing $g$ further

\footnotetext{
${ }^{12}$ This condition appears stronger at first glance since it involves the whole set of zero-profit pooling bundles, $Z \Pi\left(p_{p}\right)$ instead of the subset of default-proof bundles, $Z \Pi\left(p_{p}, g_{2}\right)$. To see the equivalence between the two conditions, note that if, on the one hand, $A^{\prime} \in Z \Pi\left(p_{p}, g_{2}\right)$, then obviously the condition states that high ability agents must prefer $B$ to $A^{\prime}$. If on the other hand, $A^{\prime} \notin Z \Pi\left(p_{p}, g_{2}\right)$, then clearly high ability agents always prefer $B$ to $A^{\prime}$ and therefore any bundle on $Z \Pi\left(p_{p}, g_{2}\right)$. In other words, the condition that high ability agents must prefer $B$ to $A^{\prime}$ does not impose any constraint when $A^{\prime} \notin Z \Pi\left(p_{p}, g_{2}\right)$. Both conditions are thus equivalent.
} 
until it reaches $g_{2}$ does not affect the nature of the separating equilibrium: a unique contract that would attract only high types while low types remain unskilled is not an option here, simply because when $g_{2}>g_{2}^{\prime}$, the outside option has less value for low ability agents than $\left(Y_{f}^{l *}(g), Y_{s}^{l *}(g)\right)$.

Summing up, apart from the fact that $g$ must be greater than or equal to either $g_{2}$ or $g_{2}^{\prime}$, a sufficient condition for a separating equilibrium to exist has to be imposed on high ability agents' preferences.

Condition $C_{S}$ : If $g_{2}<g_{2}^{\prime}$, high ability agents prefer allocation $B$ to allocation $A^{\prime}$. If $g_{2} \geq g_{2}^{\prime}$, high ability agents prefer allocation $B_{h}^{\prime}$ to allocation $A^{\prime}$.

As explained previously, the reason why condition $C_{S}$ is decomposed into two cases is that when $g_{2}<g_{2}^{\prime}, B$ is the relevant contract for a separating equilibrium, while on the other hand, if $g_{2} \geq g_{2}^{\prime}$, $B_{h}^{\prime}$ is the relevant contract.

The fact that condition $C_{S}$ is sufficient but not necessary for the existence of a pooling equilibrium when $g \geq \min \left\{g_{2}, g_{2}^{\prime}\right\}$ is due to the case where $g_{2} \geq g_{2}^{\prime}$. Indeed, if $g_{2} \geq g_{2}^{\prime}$, condition $C_{S}$ is necessary and sufficient only for $g=g_{2}^{\prime}$, while it is only sufficient for $g>g_{2}^{\prime}$. In other words, even though condition $C_{S}$ is not met, a separating equilibrium may exist for levels of $g$ larger than $g_{2}^{\prime}$. This is due to the fact that as $g$ increases, $H^{*}$ is no longer equal to $B_{h}^{\prime}$, and actually becomes more desirable than $B_{h}^{\prime}$. Therefore, even though $A^{\prime}$ is preferred to $B_{h}^{\prime}, H^{*}$ may eventually be preferred to $A^{\prime}$, so that a separating equilibrium emerges. Of course, if $g_{2}<g_{2}^{\prime}$, condition $C_{S}$ is both necessary and sufficient because for any $g \geq g_{2}$, the separating contract $B$ is offered at equilibrium.

The following proposition summarizes this discussion.

Proposition 4 If condition $C_{S}$ is satisfied, a unique separating equilibrium exists for min $\left\{g_{2}, g_{2}^{\prime}\right\} \leq$ $g \leq 1$.

- If $g_{2}<g_{2}^{\prime}$, banks offer a unique contract which corresponds to $B$ and that attracts only high ability agents. If condition $C_{S}$ does not hold, no equilibrium exists.

- If $g_{2} \geq g_{2}^{\prime}$, banks offer a pair of contracts $L^{*}$ and $H^{*}$ which are accepted respectively by low and high ability agents.

In Figure 6, $\min \left\{g_{2}, g_{2}^{\prime}\right\}=g_{2}^{\prime}$. The pooling equilibrium thus emerges for values of $g$ that define default proof spaces whose origin lie on the lighter part of $G$, i.e. $g_{2}^{\prime} \leq g \leq 1$. For the level of default penalty $g$ represented in Figure 6, the contract accepted by low ability agents yields the consumption bundle $L^{*}$, while the contract accepted by high ability agents yields the consumption bundle $H^{*}$.

From the discussion of the conditions under which the equilibrium is separating, it turns out that the welfare implications of raising the severity of default penalties are at worst neutral (when 


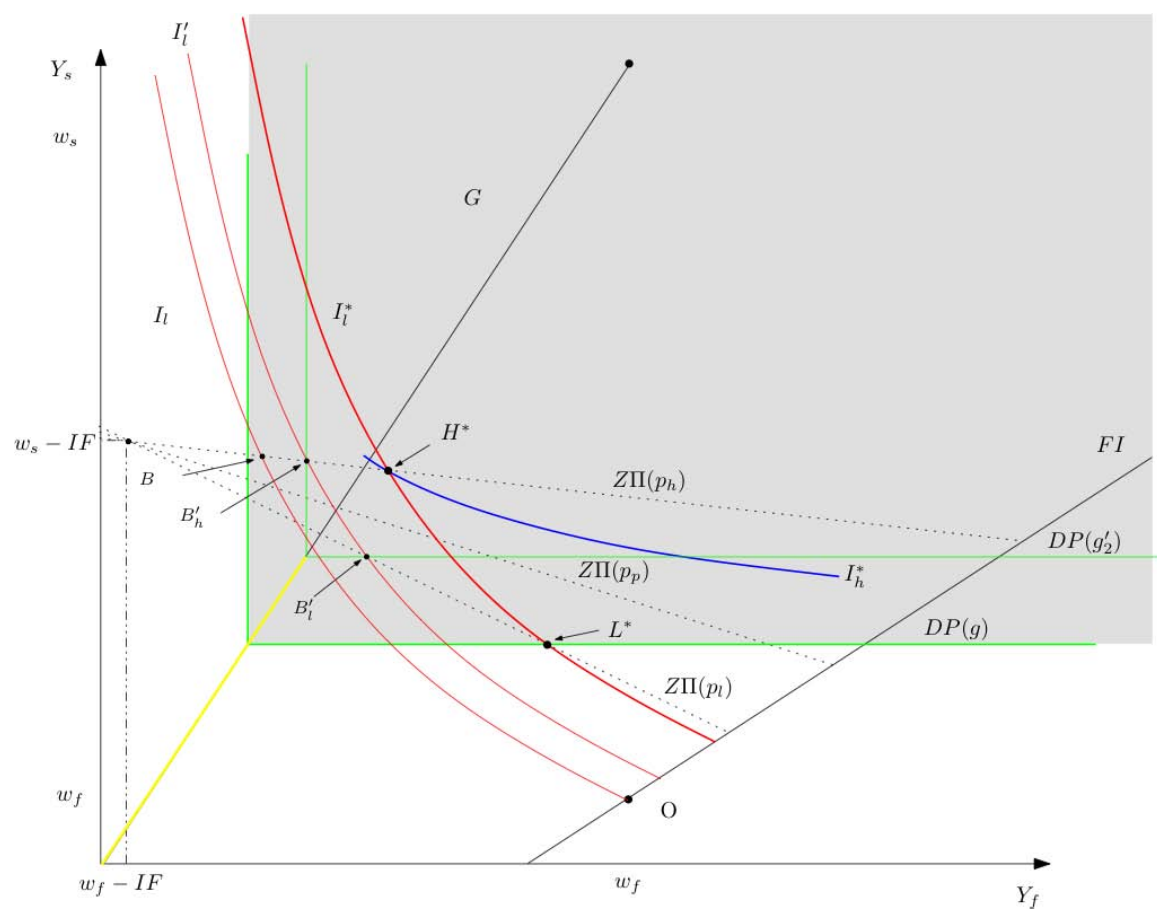

Figure 6: Separating equilibrium $\left(g>g_{2}^{\prime}=\min \left\{g_{2}, g_{2}^{\prime}\right\}\right.$, condition $B_{h}^{\prime} A$ ' is met $)$

$g_{2}<g_{2}^{\prime}$ ), and at best, welfare improving for all types of agents (when $g_{2}>g_{2}^{\prime}$ ). This is in contrast to what happens at the pooling equilibrium, where increasing $g$ benefits to high ability agents while it reduces the utility of low ability agents.

To conclude the analysis, let us consider the possibility that a contract involving the riskless interest rate $i$ in both states of the world is default-proof. This implies that $g \geq I F / w_{f}$, i.e. banks manage to recover the investment in case of failure. Obviously, banks will offer loans to students in this case. What remains to be shown is what type of contracts will be offered at equilibrium. In the discussion of Definition 9, we showed that $g_{2}^{\prime}<I F / w_{f}$. Therefore, $g \geq I F / w_{f}>g_{2}^{\prime} \geq \min \left\{g_{2}, g_{2}^{\prime}\right\}$ implies from Proposition 4 that the equilibrium is separating. Furthermore, unlike the contract $(I F, I F)$, the separating equilibrium involves some insurance. Thus, when banks are able to offer contracts that allow them to recover the investment in each state of the world, an equilibrium always exists, is separating and involves insurance.

Summing up our findings, we have characterized the outcome corresponding to each possible level of default penalties. Indeed, the intervals stated in Propositions 1 to 4 provide a proper partition of the domain of $g$, i.e. [0,1]. As Proposition 5 shows, by gathering Propositions 1 to 4 , one can thus conclude that each type of equilibrium exists for mutually exclusive intervals of $g$. In other words, each equilibrium emerges for different values of $g$ and is thus unique. 
Proposition 5 Gathering Propositions 1 to 4 and assuming that condition $C_{S}$ is satisfied, the game entails three possible scenarios:

1. $C_{1}$ (hence $C_{2}$ ) and $C_{1}^{\prime}$ apply. The relevant intervals and their corresponding equilibria are then:

- $\left[0 ; g_{0}^{p}[\right.$, unique credit rationing equilibrium

- $\left[g_{0}^{p} ; \min \left\{g_{1}, g_{1}^{\prime}, g_{1}^{\prime \prime}\right\}[\right.$, unique pooling non-insuring equilibrium

- $\left[\min \left\{g_{1}, g_{1}^{\prime}, g_{1}^{\prime \prime}\right\} ; \min \left\{g_{2}, g_{2}^{\prime}\right\}[\right.$, no equilibrium in pure strategies

- $\left[\min \left\{g_{2}, g_{2}^{\prime}\right\} ; 1\right]$, unique separating equilibrium

2. Either $C_{1}$ or $C_{1}^{\prime}$ does not apply, but $C_{2}$ does. The relevant intervals and their corresponding equilibria are then:

- $\left[0 ; g_{0}^{p}[\right.$, unique credit rationing equilibrium

- $\left[g_{0}^{p} ; \min \left\{g_{2}, g_{2}^{\prime}\right\}[\right.$, no equilibrium in pure strategies

- $\left[\min \left\{g_{2}, g_{2}^{\prime}\right\} ; 1\right]$, unique separating equilibrium

3. $C_{2}$ (hence $\left.C_{1}\right)$ do not apply. The relevant intervals and their corresponding equilibria are then:

- $\left[0 ; g_{2}[\right.$, unique credit rationing equilibrium

- $\left[g_{2} ; 1\right]$, unique separating equilibrium.

Credit rationing results under each possible scenario for low values of $g$. For the existence of a market that however fails to provide insurance, we need to impose the necessary and sufficient conditions $C_{1}$ and $C_{1}^{\prime}$, which, as previously mentioned, limit the degree of risk aversion of both types of agents. The reason is that, if individuals were more risk averse, they simply would not accept non-insuring contracts. In fact, large risk aversion of high ability agents may prevent the existence of a separating equilibrium as well, since as we have seen, their contract involves very low levels of insurance.

Let us conclude this section with a welfare comparison of the equilibria. While credit rationing is clearly Pareto dominated by pooling and separation, the separating equilibrium does not always Pareto dominate pooling. More precisely, when $g_{2}<g_{2}^{\prime}$, pooling provides low ability agents with more utility than the separating equilibrium, while the opposite is true for high ability agents. In contrast, when $g_{2}^{\prime}<g_{2}$, separation can dominate pooling, for example in the pooling equilibrium that emerges when $g$ tends to $g_{1}^{\prime \prime}$. It is therefore delicate to advocate in favor of a particular level of default penaly and its corresponding equilibrium. 


\section{Comparative statics}

The model can be also used to explain two additional and distinct stylised facts. First, according to Lochner \& Monge-Naranjo (2008), the rising returns to higher education in the United States provide an explanation for the dramatic increase in private lending. Our model can also be used to show that private loans are more likely to be offered the higher the return to education in case of success.

Second, it is observed that most private student loans are actually subsidised by governments (Shen \& Ziderman (2007)). Our model allows us to show that the introduction of such subsidies does indeed improve the case for private lending.

Third, the model also allows us to discuss the case for public income contingent loans. We show that governments can offer pooling insuring loans provided they prohibit competition or lend at lower interest rates than the market, so that the program shows a budget deficit.

We start by analysing the impact of exogenous changes in the wage in case of success. Then we study the role of an exogeneous cash inflow used to subsidize the interest rate $i$. Finally, we refer to the case for public income contingent student loans.

\subsection{Role of the wage in case of success}

Changes in $w_{s}$ affect the location of the zero profit loci (4). They also change the slope of $G\left(w_{s} / w_{f}\right)$ and thus the location of the default proof space $D P(g)$.

If $w_{s}$ increases, income after default in case of success $(1-g) w_{s}$ increases and $D P(g)$ becomes smaller $\left(G\right.$ becomes steeper while $(1-g) w_{f}$ does not change). For a unit increase in $w_{s}, D P(g)$ moves upwards by $(1-g)$. Yet, the zero profit loci move up by 1 unit, so that (additional) zeroprofit contracts become available inside $D P(g)$. The reason is that the bank is able to offer better conditions in case of success compared to the default option, $(1-g) w_{s}$. Indeed, a borrower who repays her loan benefits from the whole wage increase, whereas a defaulter would only increase her consumption by a fraction $(1-g)$ of that increase. Individuals will be less prone to default and this makes it more likely for the market to exist. The effect of increasing wages in case of success is thus similar to a decrease in interest rates, accounting for the additional effect that $D P(g)$ also moves. Summing up, higher wages in case of success improve the case for private student loans, with everything else equal.

\subsection{Role of a subsidy on the interest rate}

Suppose that the government benefits from an exogenous inflow of cash that it uses to subsidize banks' costs of borrowing $i$. Because of Bertrand competition, this lower cost will immediately 
be transferred to the borrower: interest rates will be lower and allow higher consumption bundles in case of failure and success. Lower interest rates, on the other hand, make it less profitable to default. Thus the existence of the market is compatible with lower levels of the penalty $g$ when banks are subsidized. In other words, subsidies of this kind can take the economy from a credit rationing equilibrium to a pooling equilibrium.

Graphically, the reduction in $I=1+i$ translates into an upward shift of the zero profit loci, while their slope remains unaltered (see Equation (4)). Given $g$, the fall in $i$ thus incites banks to offer contracts, as some of those contracts now generate non-negative profits despite asymmetric information and ex-post moral hazard. Moreover, subsidizing $i$ will make the separating equilibrium more easy to obtain.

Interestingly, this result suggests that governments may not need to organize income contingent loans themselves, they might just strongly subsidize banks, and the competitive equilibrium would provide insurance for low ability agents.

\subsection{Public income contingent loans}

Unlike private banks, it is observed that governments offer pooling contracts with insurance, such as point $I$ on Figure 3. According to the model, there are two reasons why this can be done. On the one hand, governments, unlike banks, can act alone on this market. By forbidding private lenders to offer student loans, governments can prevent deviations that would attract high ability agents out of the pooling insuring contract, and thus maintain the sustainability of the system. On the other hand, if private banks are allowed to offer student loans, the government can use budget revenues in order to lend at lower interest rates. According to the analysis undertaken in the previous subsection, this will shift the pooling zero-profit locus of the government upwards, improving the case for public (and not private) loans.

\section{Conclusion}

In this paper we have proposed a model to analyse the student loan market and explain its potential failures, along with other important stylised facts. We have considered risk averse agents who need to borrow in order to invest in education and who are heterogeneous in the probability of success. A particularity of our model is that it combines adverse selection with the possibility for agents to repay their loan only if this is less costly than incurring default. Default penalties are determined by law and are defined here as the share of the wage that banks are allowed to garnish. Banks are perfectly competitive and are unable to observe the agents' ability. They offer menus of loan contracts that may include insurance against the eventuality of failure. 
In this framework, we have characterized the outcome corresponding to each possible level of default penalties and we have shown that when an equilibrium exists, it is unique.

First, if default penalties are sufficiently low, banks do not offer student loans at equilibrium. This market failure is commonly known as credit rationing, and in our model, it results from the combination of ex post moral hazard and adverse selection.

Second, higher default penalties can yield a pooling equilibrium. Banks offer a single contract that is non-insuring. Because agents are risk averse, this equilibrium corresponds to a second type of market failure, to wit lack of insurance. If risk aversion is very high, the pooling equilibrium may not exist.

Finally, if default penalties are sufficiently large, the equilibrium is separating and involves some insurance. More precisely, if default penalties are sufficiently large, the market provides low ability agents with income contingent loans, which they may accept or not. High ability types, on the other hand, enjoy at this equilibrium a lower level of insurance than at the pooling equilibrium. Increasing the severity of default penalties is at worst neutral and at best it increases the welfare of both types by allowing for greater insurance. However, the welfare comparison of both types of equilibrium is delicate, as the separating equilibrium does not always Pareto dominate the pooling equilibrium.

How large is, in reality, the penalty for default? It is difficult to say. Effective default penalties depend not only on the law, but also the cost of law enforcement and the regulation of personal bankruptcy. There are also cultural and psychological factors that affect the perceived size of the penalty. The fact that, when we observe the existence of a market of student loans these are of the pooling-non-insuring type, may be interpreted as evidence that default penalties are of intermediate size. However, although in our model there is no government, the student loan market is in general heavily intervened. Thus, what we generally observe is not a pure market outcome.

We have used the model to show how subsidies can bring about private lending. Also, we have shown how an exogenous increase in the wage in case of success can improve the case for private student loans for any given level of default penalties. To conclude, we have explained why governments, unlike private banks, can provide all students with the same income contingent loan contracts.

The model is certainly simple and leaves out of the scope of the analysis important aspects of credit markets such as market power, legal costs associated to collecting penalties, other costs associated to default or the role of collateral, among others. Yet, the model provides a useful benchmark and can easily be extended to account for some of these issues.

As a way of example, the model can be extended by introducing asymmetries between what defaulters pay as penalties and what banks obtain from these penalties. For instance, it could be 
costly for banks to sue defaulters. If the cost of initiating legal action is higher than default penalties when students fail, banks will only sue successful defaulters. Unsuccessful borrowers anticipate this and default with impunity. Consequently, it can be shown that a separating equilibrium can never be obtained. This is quite natural: we have attributed market failure to insufficient penalties. High legal action costs can only reinforce the market failure results.

Other issues may require less trivial extensions. For example, we could explore the impact of the introduction of an heterogeneous initial individual endowment which can be used as collateral. If collateral is observable, our qualitative results are replicated for each possible level of collateral: each collateral level corresponds to a different game. Otherwise, we face a richer model of multi-dimensional asymmetric information that needs to be studied in depth. Other avenues of research involving multiple dimensions include heterogeneous aversion levels and idiosyncratic costs of default. We leave these for future research. 


\section{References}

Barr, N. (2001). The welfare state as piggy bank : information, risk, uncertainty, and the role of the state. Oxford: Oxford University Press.

Bertola, G., Disney, R., \& Grant, C., Eds. (2006). The Economics of Consumer Credit. MIT Press.

Boadway, R. \& Keen, M. (2004). Financing new investments under asymmetric information: A general approach. CIRPEE Working Paper, (04-07).

Canton, E. \& Blom, A. (2004). Can student loans improve accessibility to higher education and student performance? an impact study of the case of sofes, mexico. CPB Discussion Papers Series, Netherlands Bureau for Economic Policy Analysis., (33).

Chapman, B. (2005). Income contingent loans for higher education: International reform. Discussion Papers of the Research School of Social Sciences, Australian National University, CEPR, (491).

Chapman, B. \& Greenaway, D. (2006). Learning to live with loans? international policy transfer and the funding of higher education. The World Economy, 29(8), 1057-1075.

Chen, H.-j. (2005). Educational systems, growth and income distribution: a quantitative study. Journal of Development Economics, 76(2), 325-353.

de la Croix, D. \& Michel, P. (2007). Education and growth with endogenous debt constraints. Economic Theory, 33(3), 509-530.

de Meza, D. \& Webb, D. C. (1987). Too much investment: A problem of asymmetric information. The Quarterly Journal of Economics, 102(2), 281-92.

Eurydice (1999). Key topics in education. Technical report, European Commission, Brussels.

Fender, J. \& Wang, P. (2003). Educational policy in a credit constrained economy with skill heterogeneity. International Economic Review, 44(3), 939-964.

Ionescu, A. F. (2007). Bankruptcy rules, college enrollment, and default incentives for student loans. Mimeo.

Jacobs, B. \& van Wijnbergen, S. J. G. (2007). Capital-market failure, adverse selection, and equity financing of higher education. FinanzArchiv: Public Finance Analysis, 63(1), 1-32.

Kehoe, T. J. \& Levine, D. K. (1993). Debt-constrained asset markets. Review of Economic Studies, $60(4), 865-88$. 
La Porta, R., Lopez-de Silanes, F., Shleifer, A., \& Vishny, R. (1998). Law and finance. Journal of Political Economy, 106(6), 1113-1155.

Lochner, L. J. \& Monge-Naranjo, A. (2008). The nature of credit constraints and human capital. NBER Working Papers Series, (13912).

Mas-Colell, Andreu, M. D. W. e. J. R. G. (1995). Microeconomic Theory. Oxford University Press.

Salmi, J. (1999). Student loans in an international perspective: The world bank experience. LCSHD Paper Series, 44.

Shen, H. \& Ziderman, A. (2007). Student loans repayment and recovery - international comparisons. Paper presented at the "Funding, Equity and Efficiency of Higher Education" Conference in Portoroz, 2007.

Stiglitz, J. E. \& Weiss, A. (1981). Credit rationing in markets with imperfect information. American Economic Review, 71(3), 393-410.

Tsiddon, D. (1992). A moral hazard trap to growth. International Economic Review, 33(2), 299-321.

Vercammen, J. (2002). Welfare-improving adverse selection in credit markets. International Economic Review, 43(4), 1017-1033.

Zeira, J. (1991). Credit rationing in an open economy. International Economic Review, 32(4), 959-72.

\section{Appendix 1: Proof of Lemma 1}

Proof. For a pooling equilibrium to exist, $Z \Pi\left(p_{p}, g\right)$ must be non-empty. Lemma 1 claims that, among all contracts that are pooling equilibrium candidates, or equivalently, among all corresponding consumption bundles $\left(Y_{f}, Y_{s}\right) \in Z \Pi\left(p_{p}, g\right)$, only the non-insured bundle $\left((1-g) w_{f}, \frac{p_{p} w_{s}-I F+\left(1-p_{p}\right) g w_{f}}{p_{p}}\right)$ emerges at the pooling equilibrium. To see why, let us consider any $\left(Y_{f}^{i}, Y_{s}^{i}\right) \in Z \Pi\left(p_{p}, g\right)$ with $\left(Y_{f}^{i}>(1-g) w_{f}\right.$ and $Y_{s}^{i}<\frac{p_{p} w_{s}-I F+\left(1-p_{p}\right) g w_{f}}{p_{p}}$, and show that there exists a profitable deviation from $\left(Y_{f}^{i}, Y_{s}^{i}\right)$, so that the latter cannot be an equilibrium. By single crossing of the two types' indifference curves, there always exists some other bundle $\left(Y_{f}^{d}, Y_{s}^{d}\right) \in D P(g)$ such that $E U\left(p_{l}, Y_{f}^{d}, Y_{s}^{d}\right)<E U\left(p_{l}, Y_{f}^{i}, Y_{s}^{i}\right)$ but $E U\left(p_{h}, w_{f}, w_{f}\right)>E U\left(p_{h}, Y_{f}^{i}, Y_{s}^{i}\right)$ and such that $E \Pi\left(p_{h}, Y_{f}^{d}, Y_{s}^{d}\right)>0$. In other words, if banks offer a pooling contract that implies a consumption bundle $\left(Y_{f}^{i}, Y_{s}^{i}\right)$, there always exists a profitable deviation, which consists in offering a contract they know that only high types would accept, and that would yield strictly positive expected profits. 
The dark shade area in Figure 3 represents such profitable deviations from $\left(Y_{f}^{i}, Y_{s}^{i}\right)$. Finally, note that $\left((1-g) w_{f}, \frac{p_{p} w_{s}-I F+\left(1-p_{p}\right) g w_{f}}{p_{p}}\right)$ is the only bundle in $Z \Pi\left(p_{p}, g\right)$ such that such a profitable deviation does not exist.

\section{Appendix 2: Existence of $g_{1}^{\prime \prime}$}

Let $\left(Y_{f}^{l *}(g), Y_{s}^{l *}(g)\right)$ the best consumption bundle in $Z \Pi\left(p_{l}, g\right)$ for a low ability agent. Let $\left(Y_{f}^{p}(g), Y_{s}^{p}(g)\right)$ be the non-insuring, pooling contract. Definition 8 states that $g_{1}^{\prime \prime}$ is such that $E U\left(p_{l}, Y_{f}^{l *}\left(g_{1}^{\prime \prime}\right), Y_{s}^{l *}\left(g_{1}^{\prime \prime}\right)\right)=E U\left(p_{l}, Y_{f}^{p}\left(g_{1}^{\prime \prime}\right), Y_{s}^{p}\left(g_{1}^{\prime \prime}\right)\right)$.

Let us consider $g=I F / w_{f}$, in which case the pooling non-insuring contract corresponds to the bundle $\left(w_{f}-I F, w_{s}-I F\right)$, the point where the zero profit loci cross. Therefore, this bundle also belongs to $Z \Pi\left(p_{l}, I F / w_{f}\right)$ and is actually the worst bundle on it. This bundle can thus only provide less utility than $\left(Y_{f}^{l *}\left(I F / w_{f}\right), Y_{s}^{l *}\left(I F / w_{f}\right)\right)$.

Let us now consider $g=g_{0}^{l}<I F / w_{f}$, which is the lowest $g$ such that $Z \Pi\left(p_{l}, g\right)$ is non-empty. In this case, $\left(Y_{f}^{l *}\left(g_{0}^{l}\right), Y_{s}^{l *}\left(g_{0}^{l}\right)\right)$ provides less utility than the non-insuring pooling contract in $Z \Pi\left(p_{p}, g_{0}^{l}\right)$.

By continuity of the utility function, there exists some $\left.g=g_{1}^{\prime \prime} \in\right] g_{0}^{l}, I F / w_{f}[$ such that $E U\left(p_{l}, Y_{f}^{l}\left(g_{1}^{\prime \prime}\right), Y_{s}^{l}\left(g_{1}^{\prime \prime}\right)\right)=E U\left(p_{l}, Y_{f}^{p}\left(g_{1}^{\prime \prime}\right), Y_{s}^{p}\left(g_{1}^{\prime \prime}\right)\right)$. 